8a 'npa · m

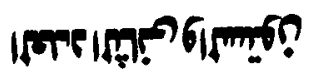
ififo 0 - ג

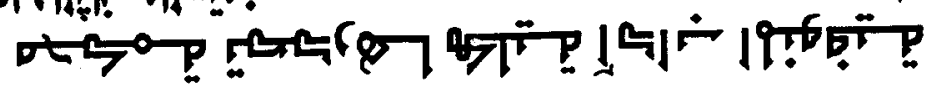

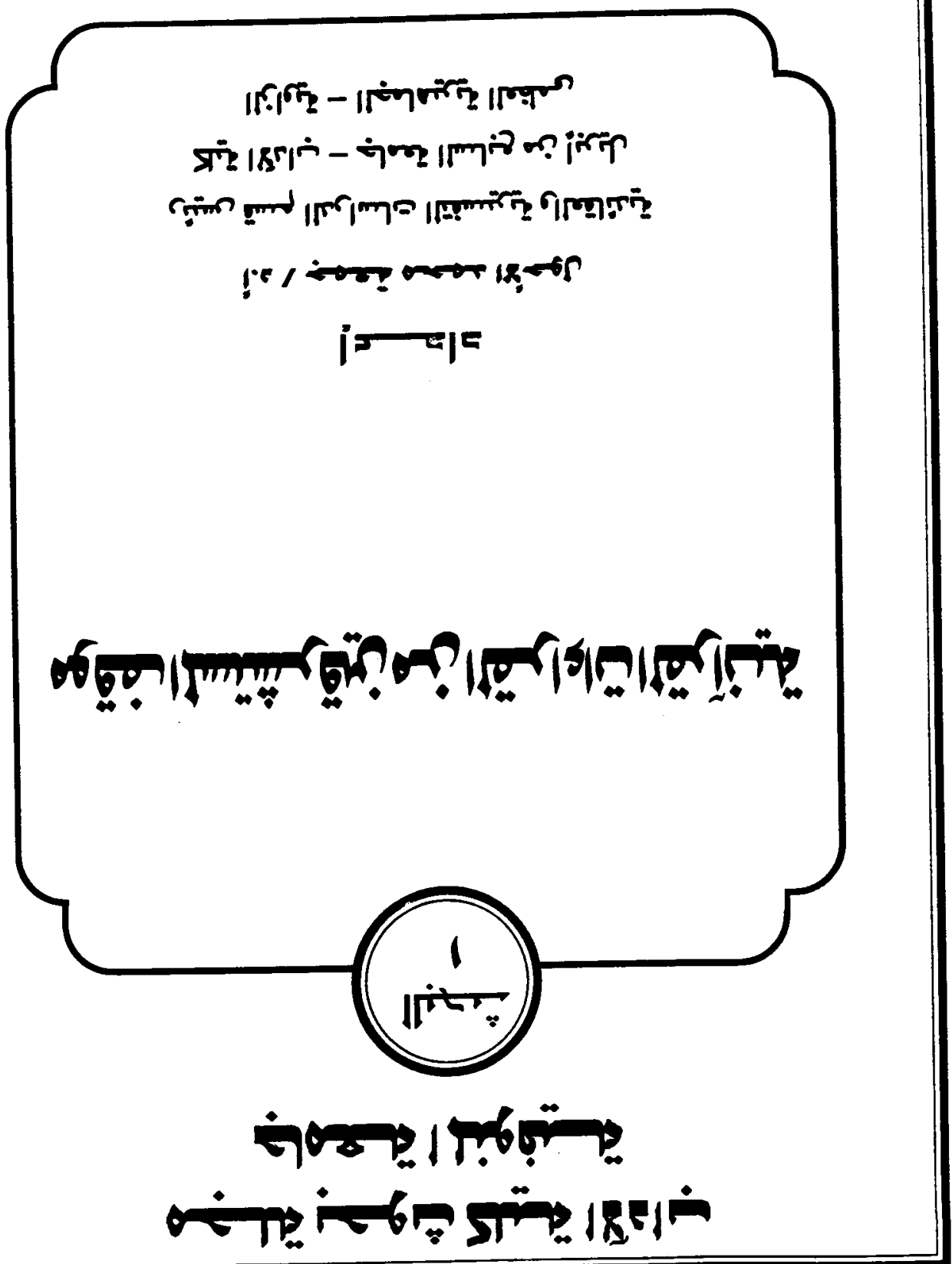




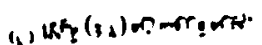

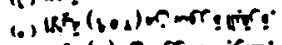

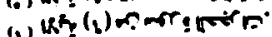

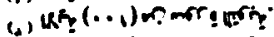

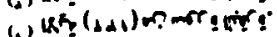

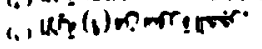

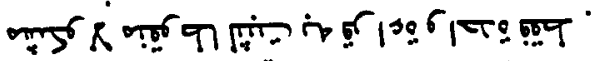

?

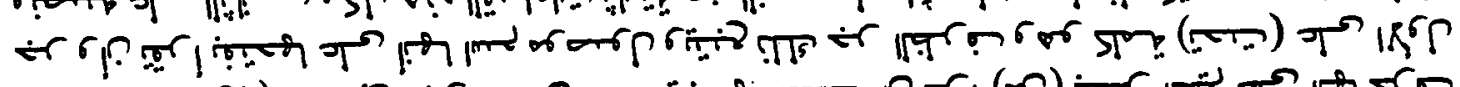

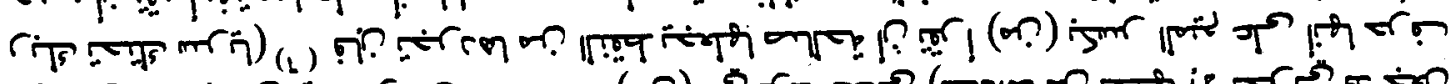

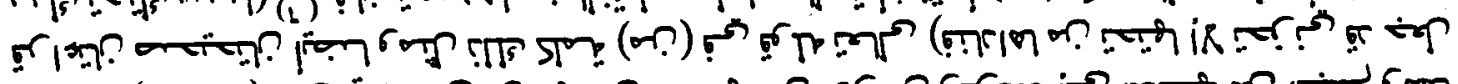
ror ( 1 (n)

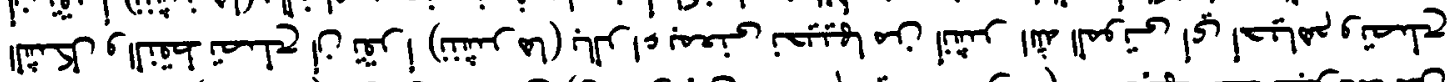

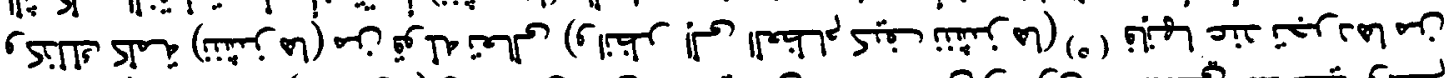

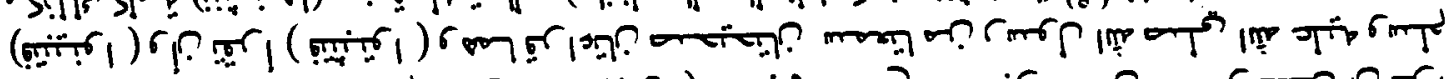
(7) याँ

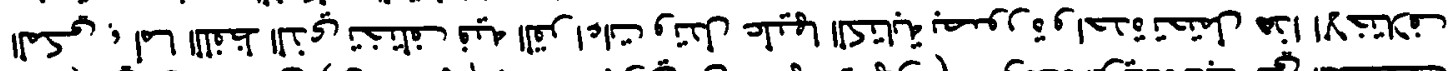

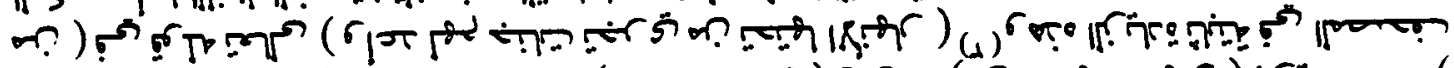
if रता iron

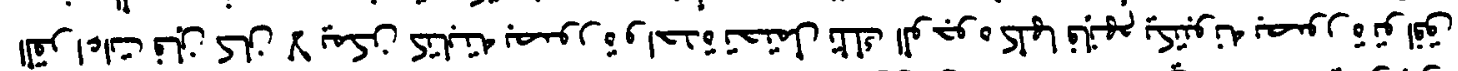
|II!़ |

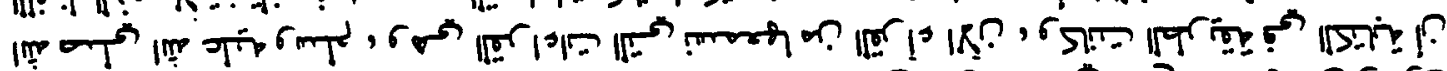

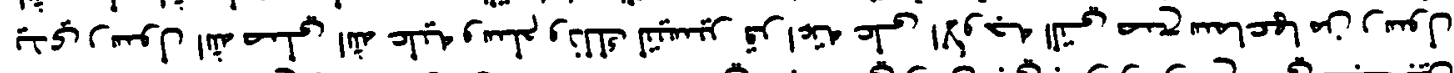

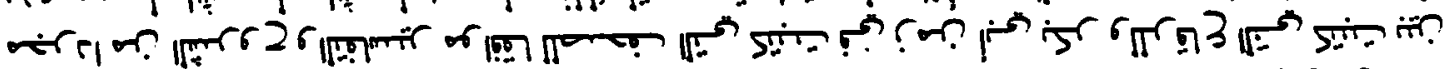

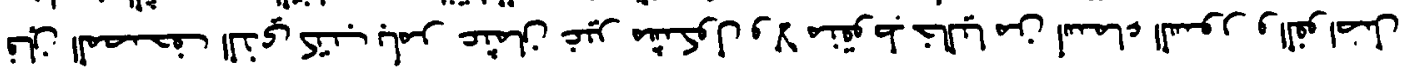

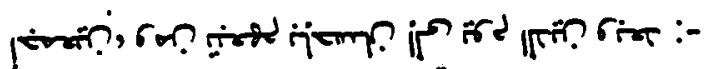
لهب

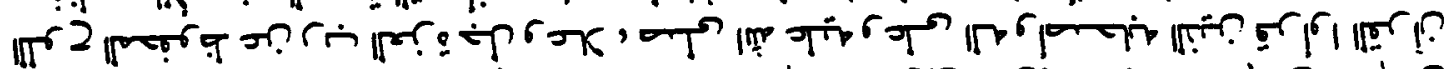

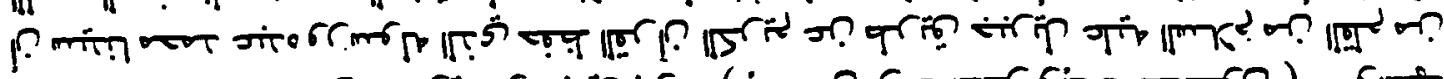

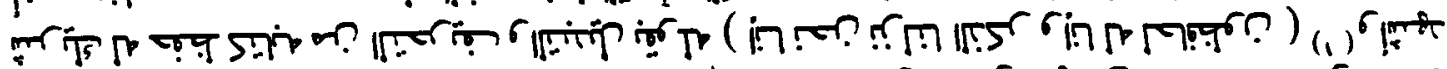
|rod

(ogn) 


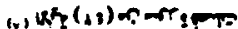

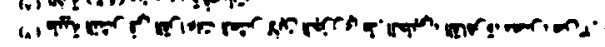

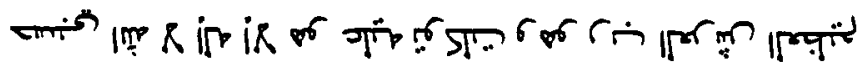

$\operatorname{1ก}$

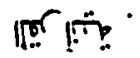

| r.

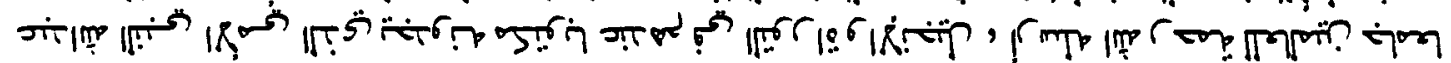

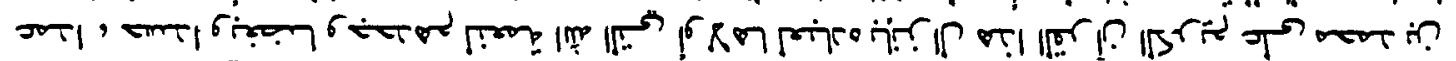

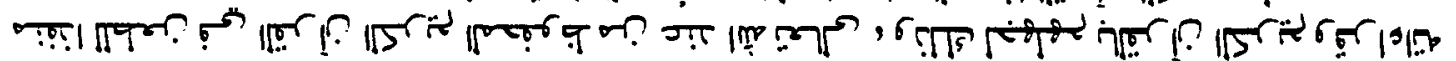

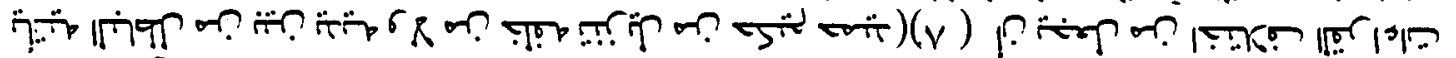

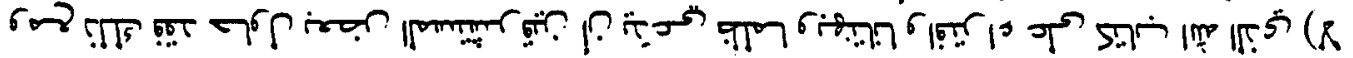

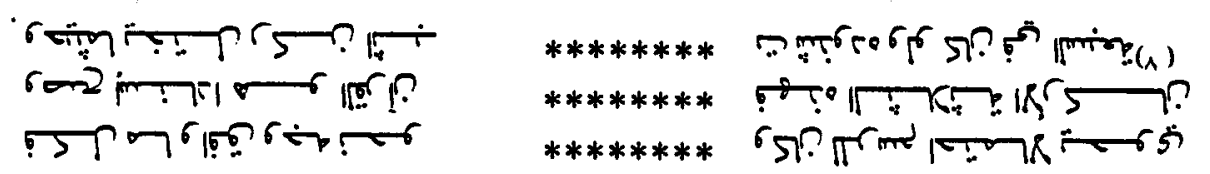

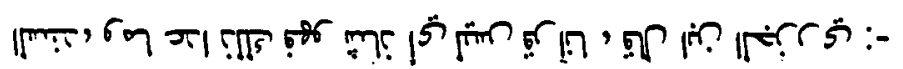

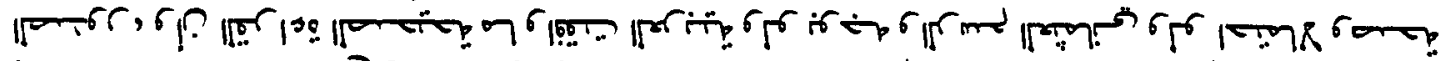

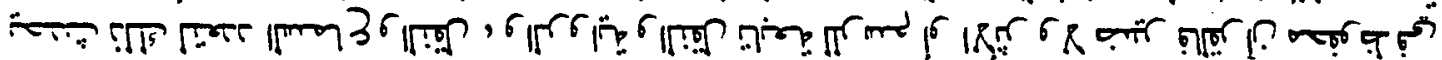

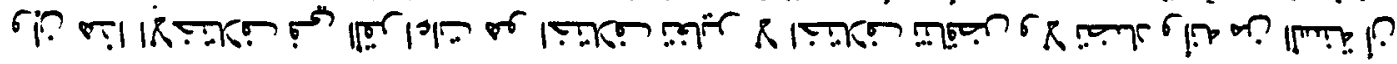




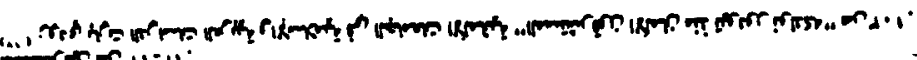

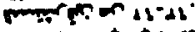

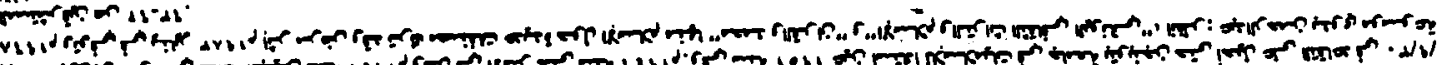

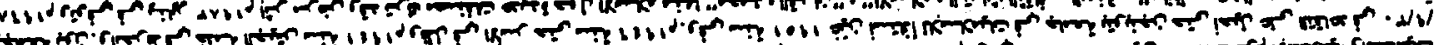
t.

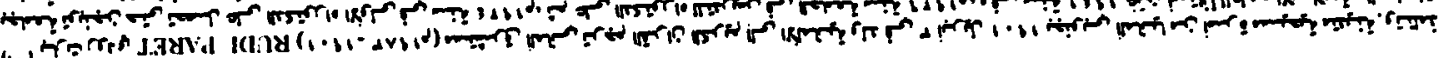
i.i.

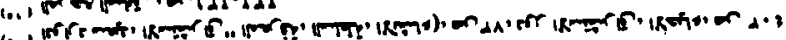

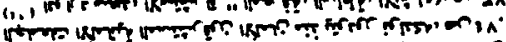

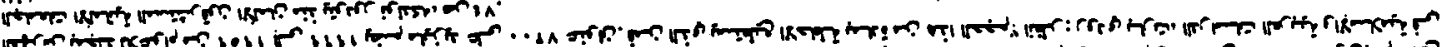
(ب) The

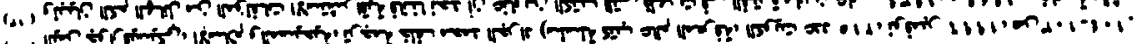

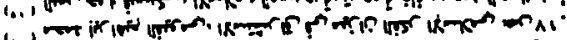

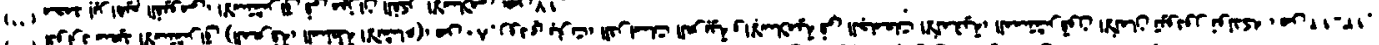

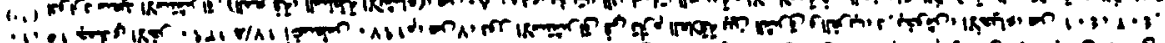

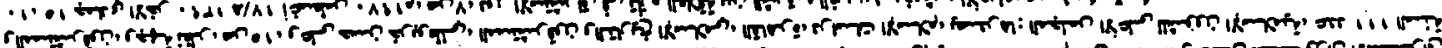

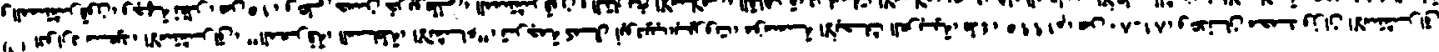

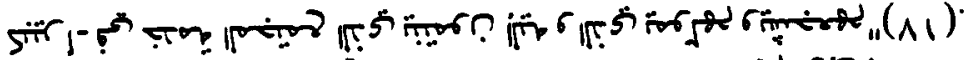

का

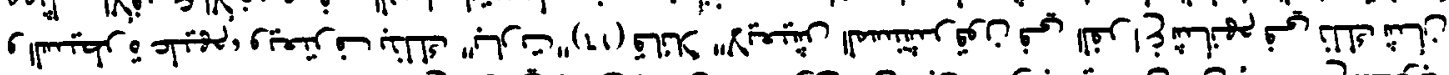

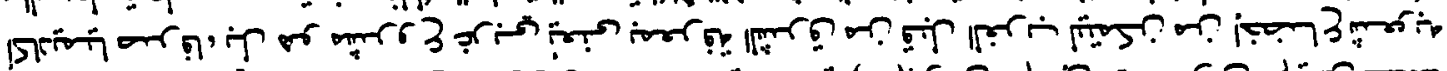

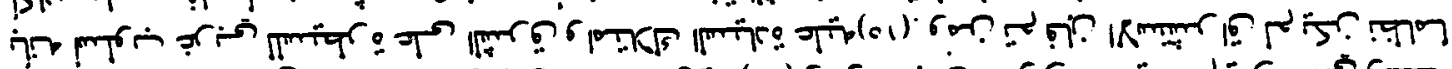

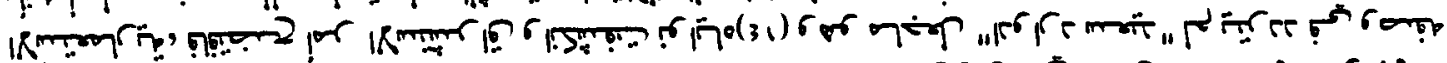

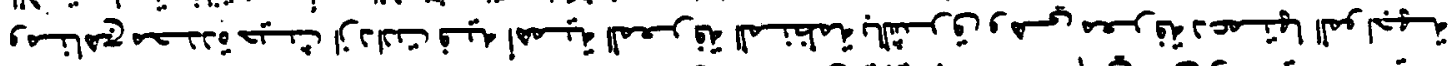

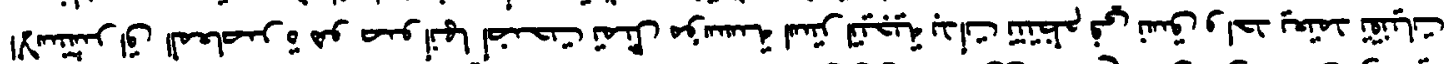

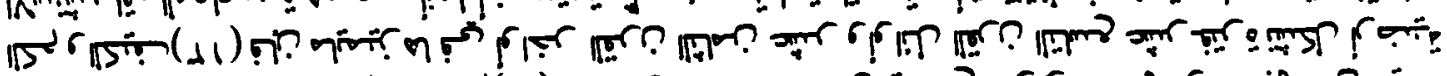

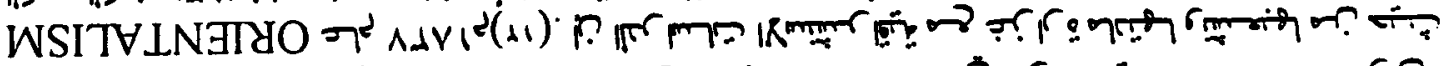

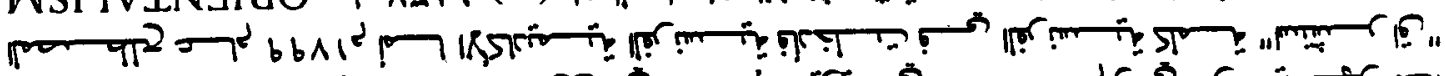

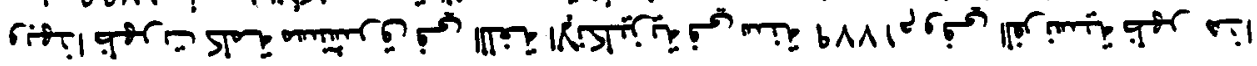

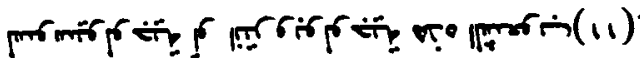

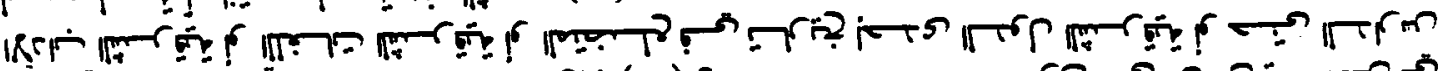

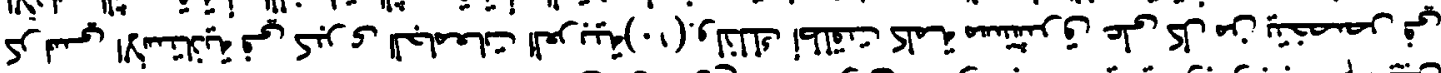

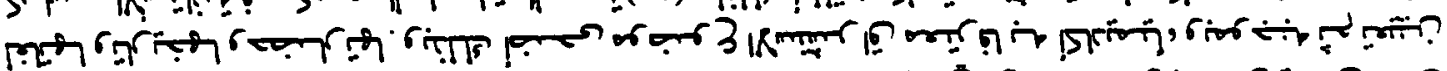

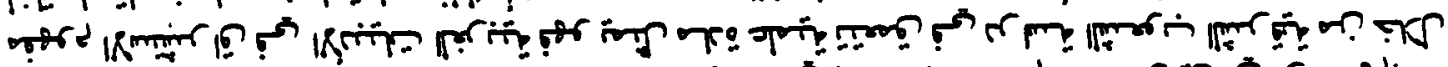
M

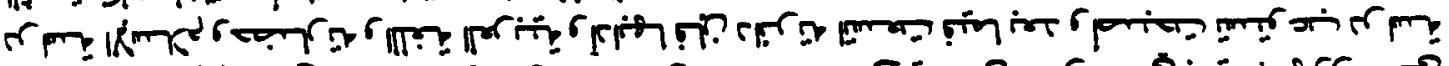

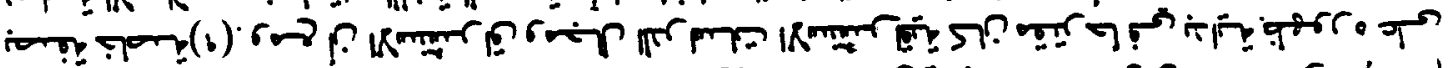

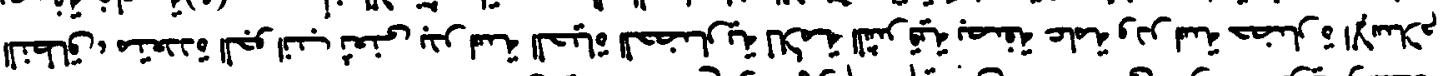

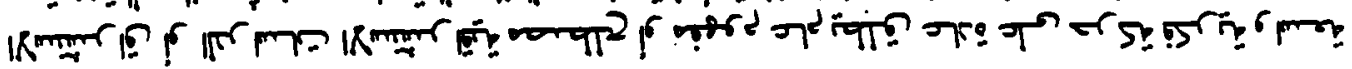

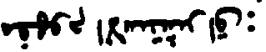

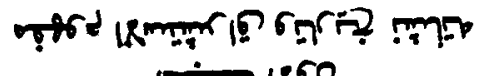

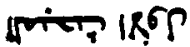




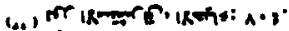

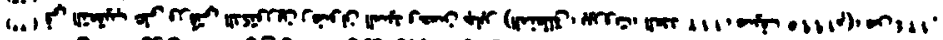

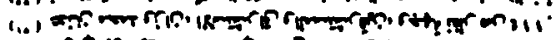

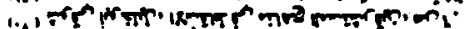

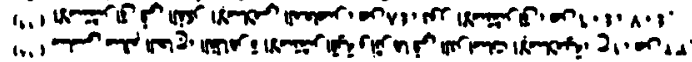

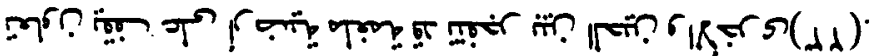

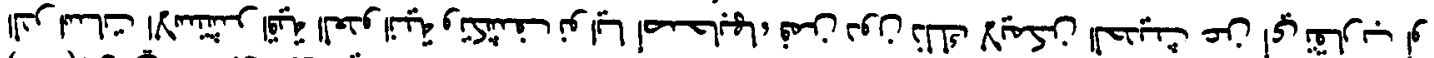

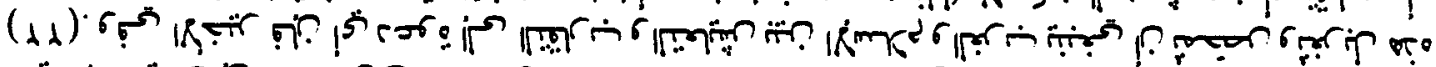

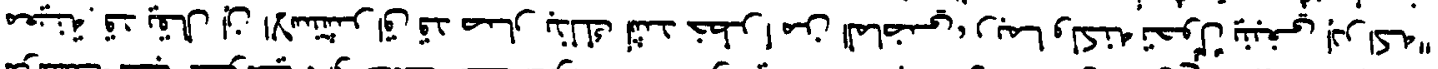

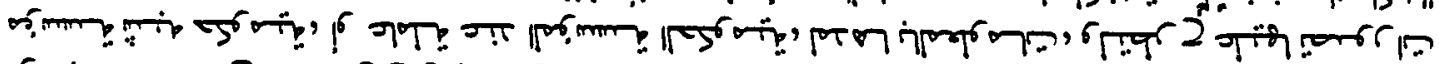

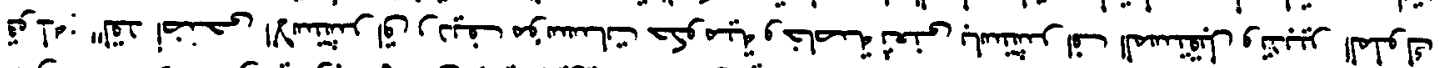
|R

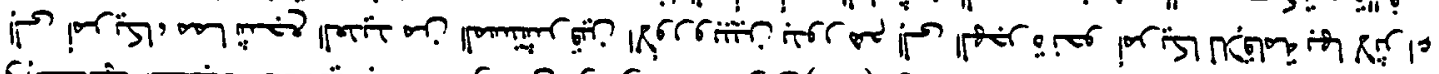

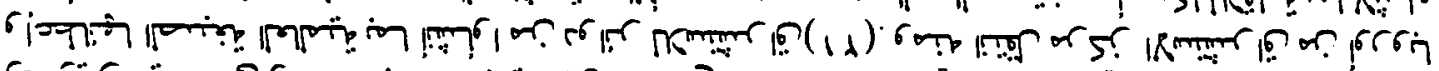

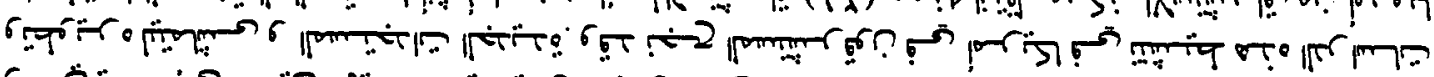

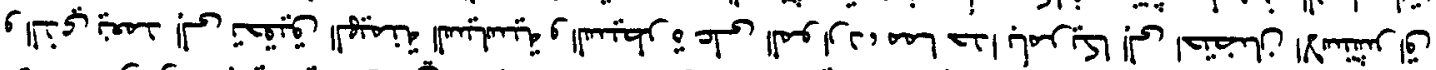

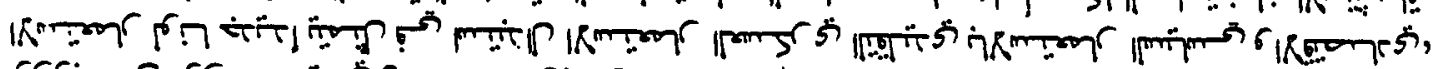

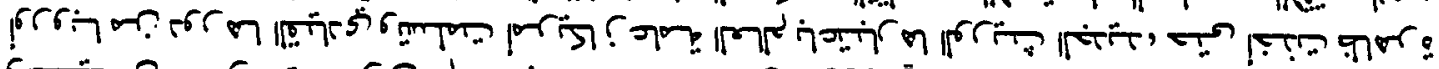

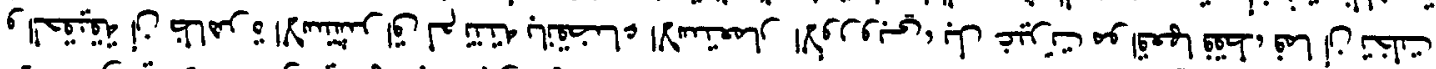
18.

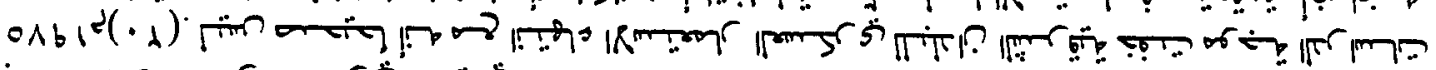

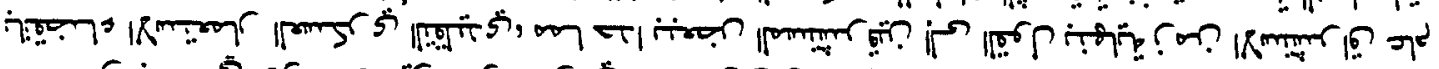
r 7क्ष |

ra

"2 r

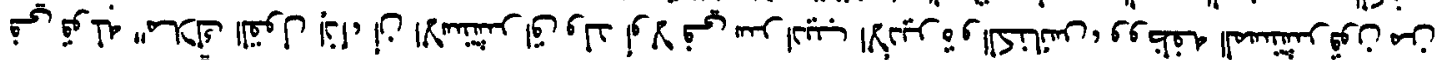

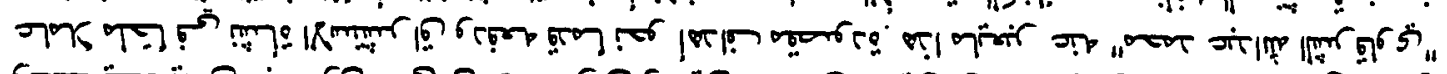

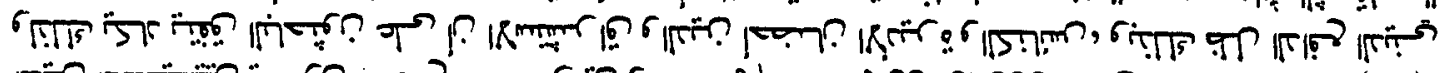

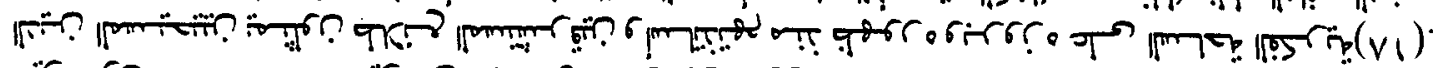

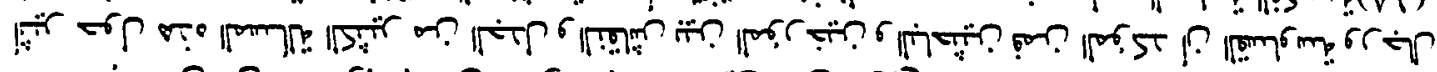
1.

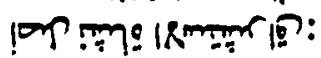





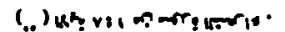

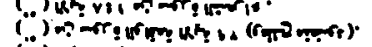

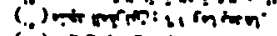

(i.)

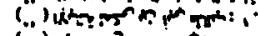

(i)

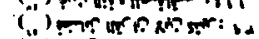

(i)

(i)

(i)

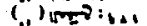

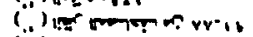

(.) IIMTT: $2 v^{\circ} v r$

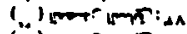

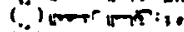

(i) lom ints.

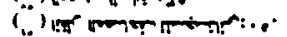

(ii)

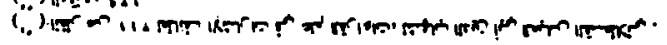

20

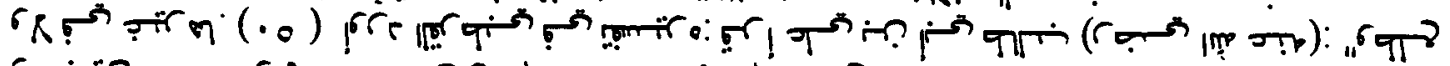

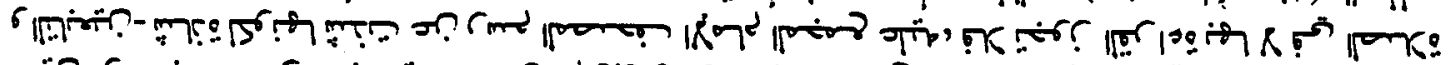

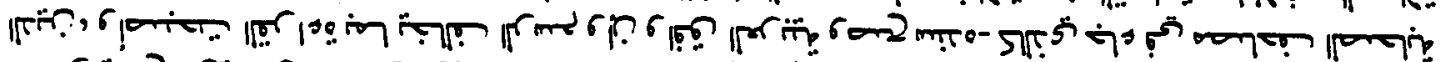

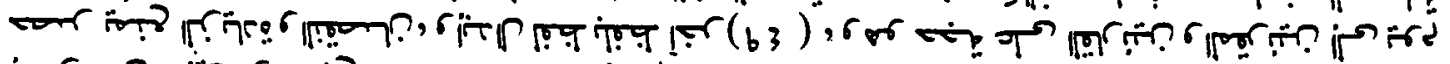

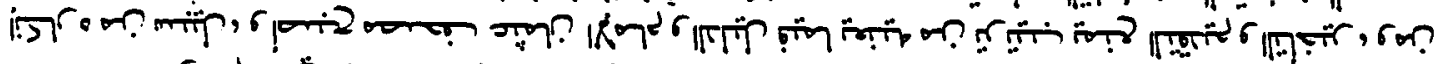

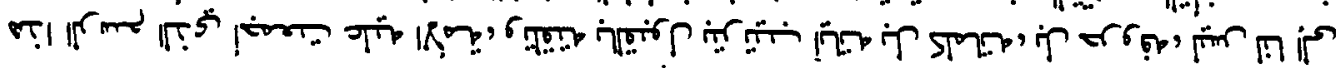
|

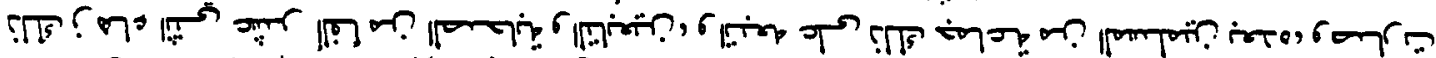

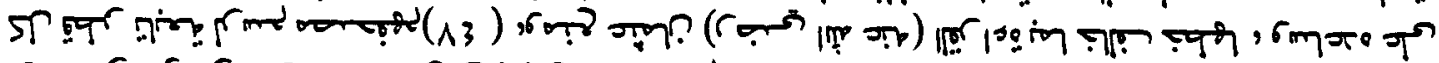

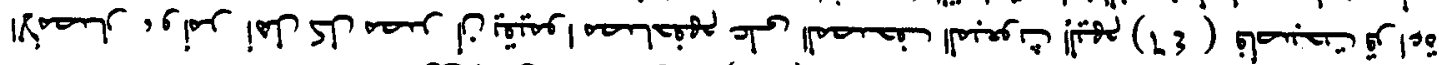

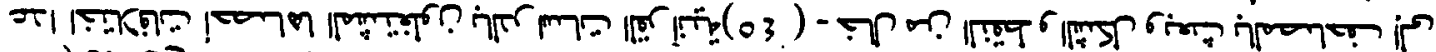

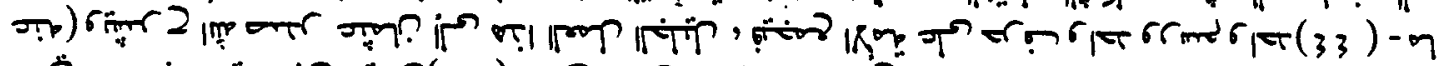
| |

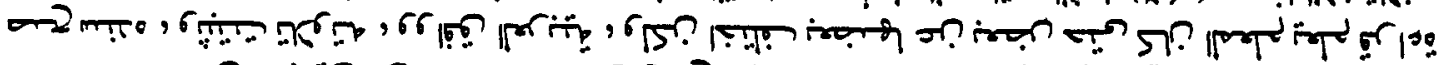

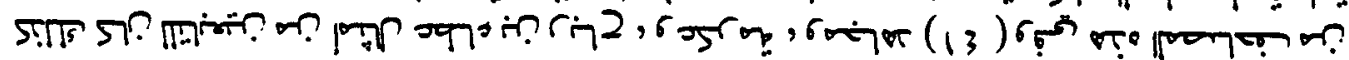

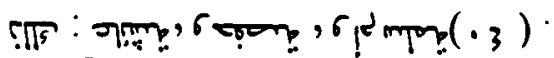

,

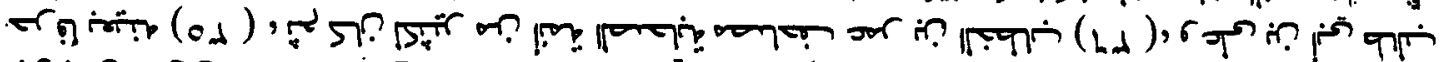

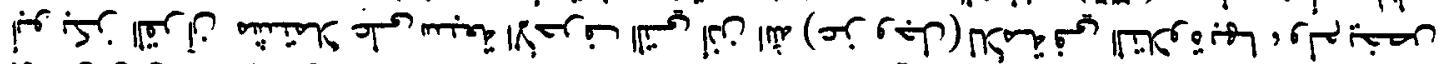

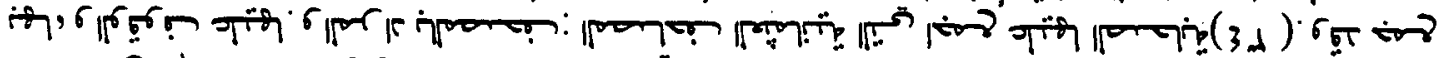

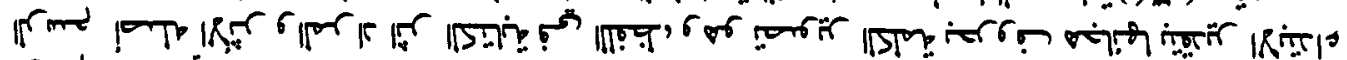

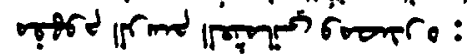




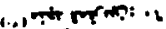

i..)

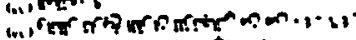

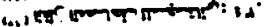

(i.)

in,

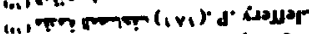

(1)

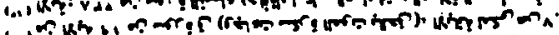

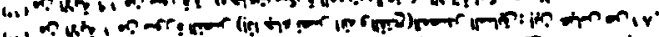

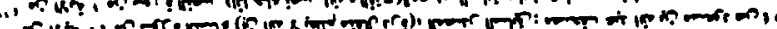

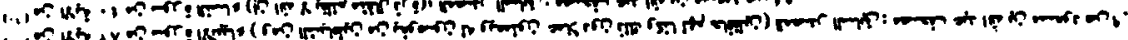

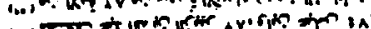

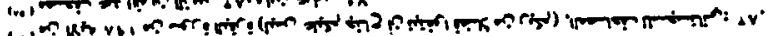

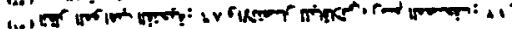

(..) )

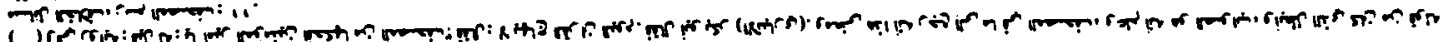

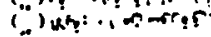

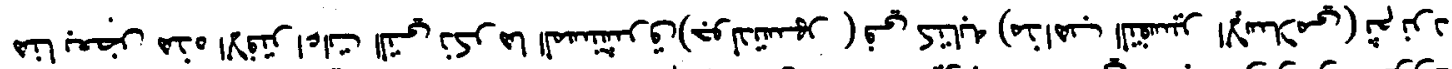
|D

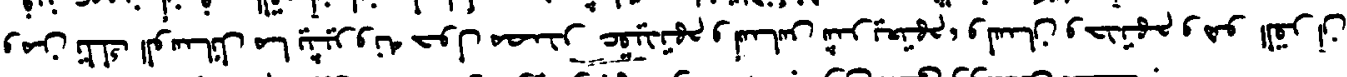
ה

م"

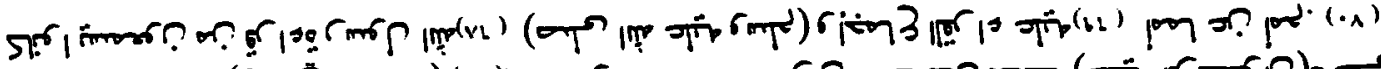

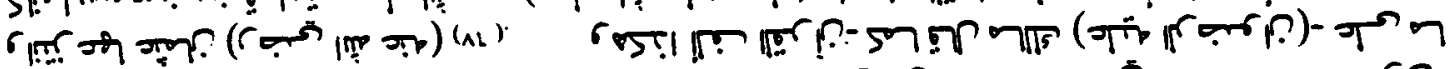

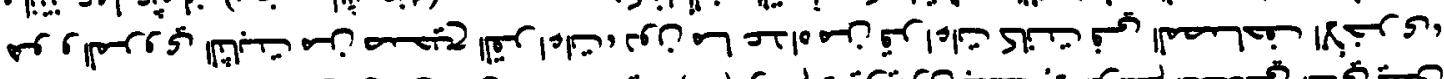

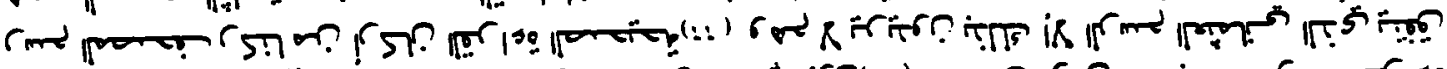

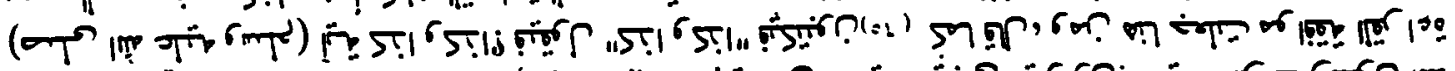

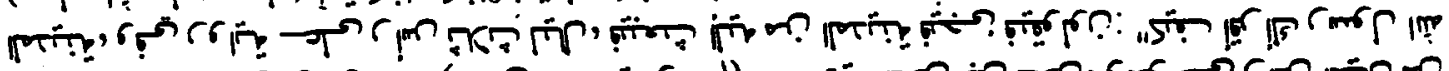

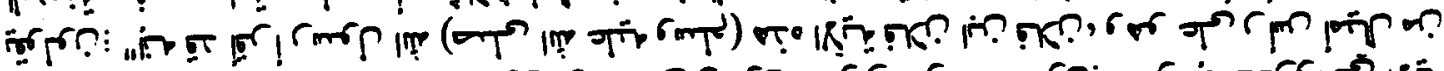

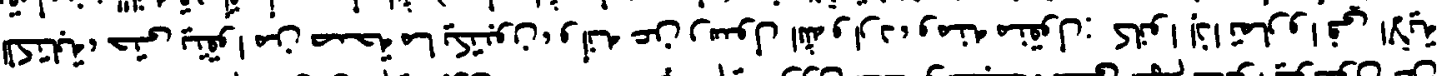

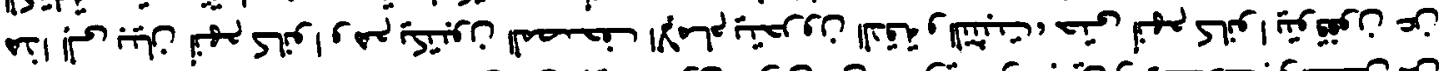

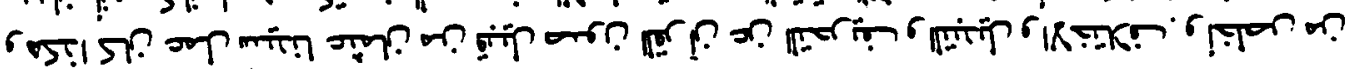

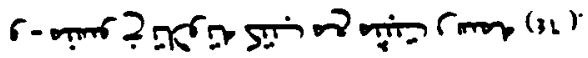

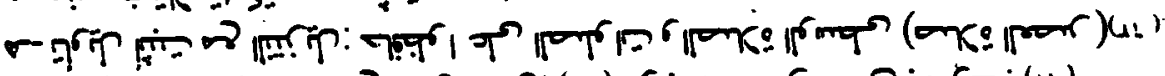

(-

2-

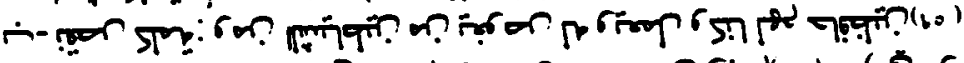

1)

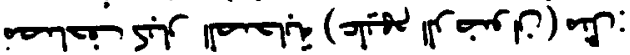

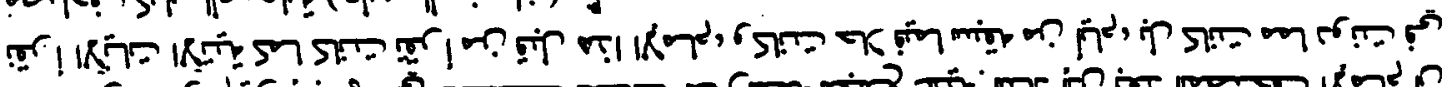

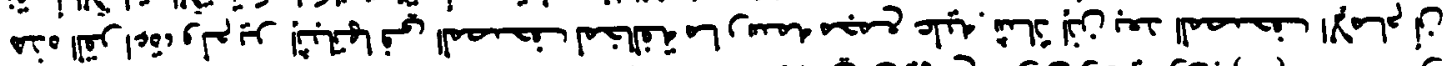
"ग $\pi^{2}$

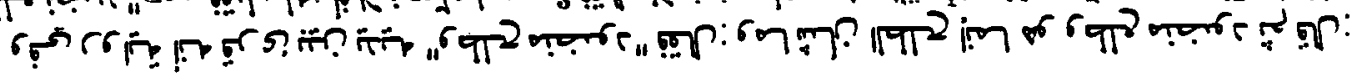




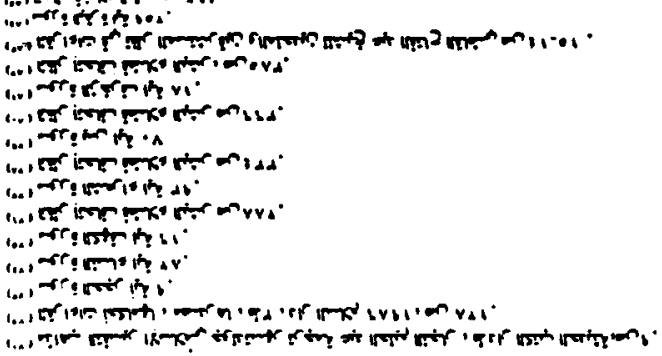

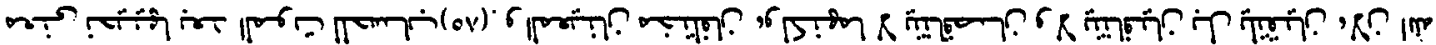

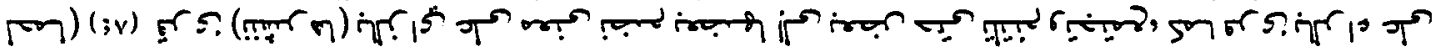

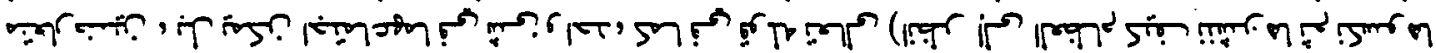

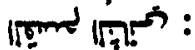

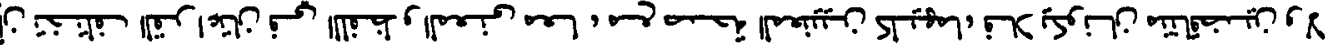

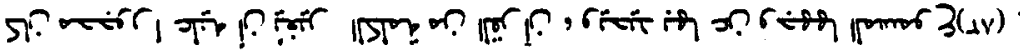

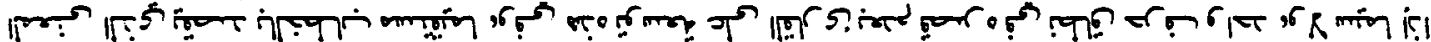

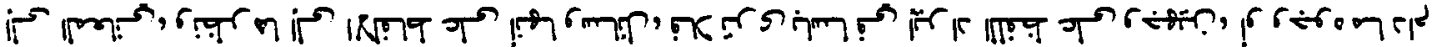

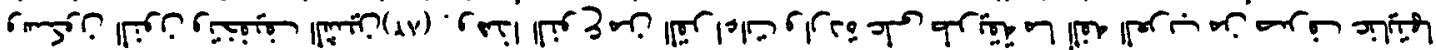

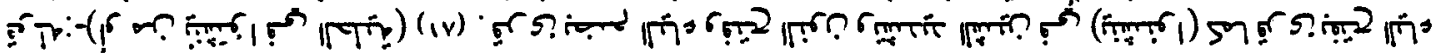

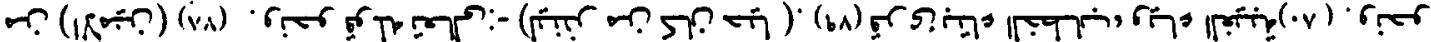

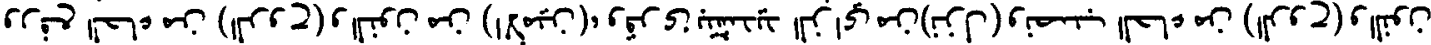

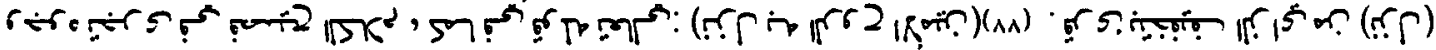

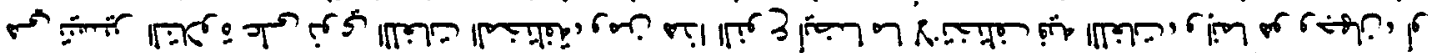
م.

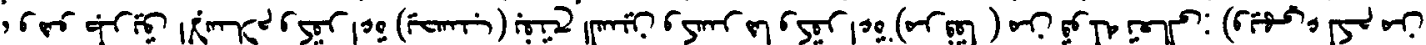

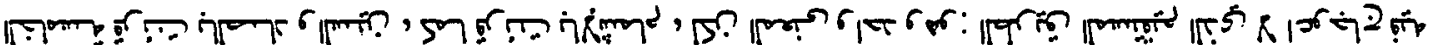
: Iremert

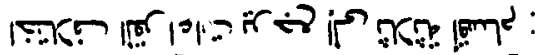

r

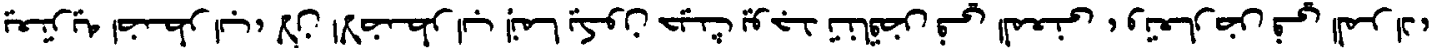

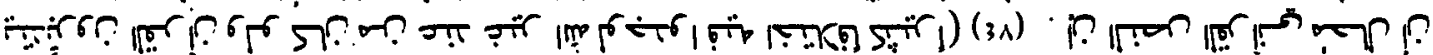

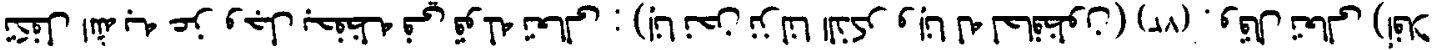

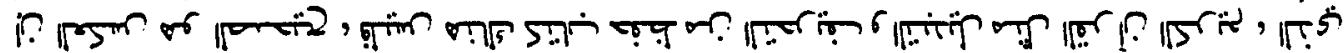

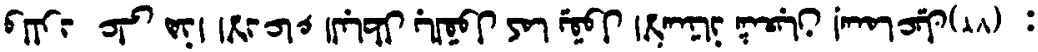

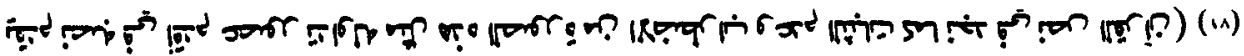

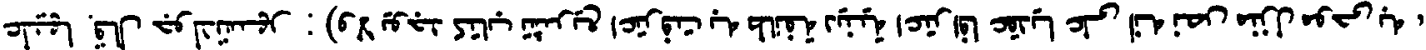




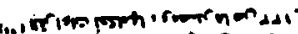

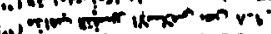

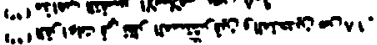

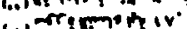

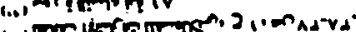

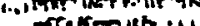

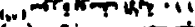

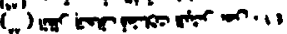

(C) Arti noth ih vi

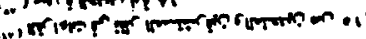

茛

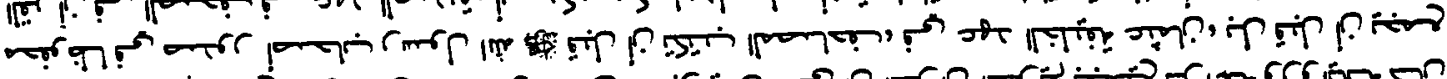

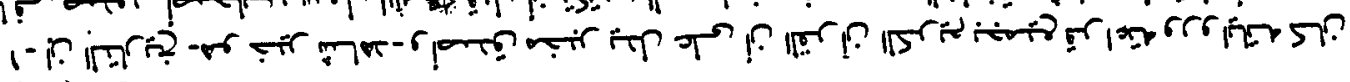

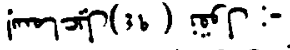

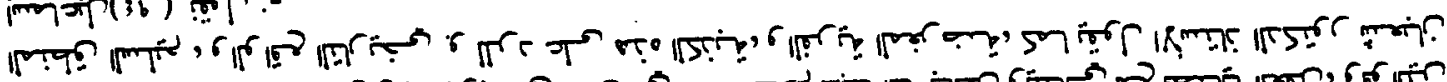

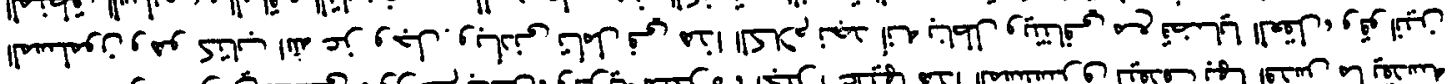

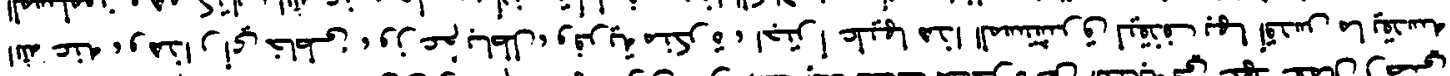

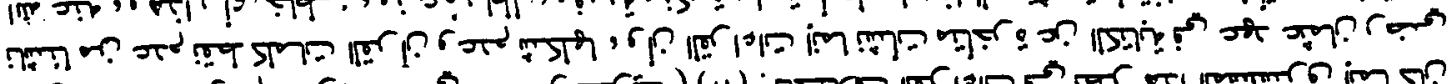

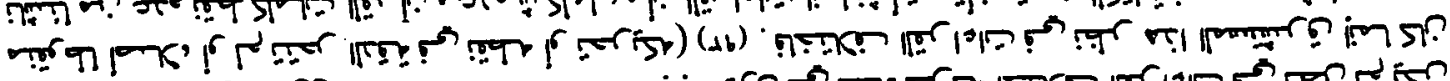

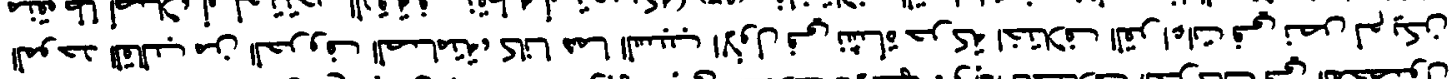

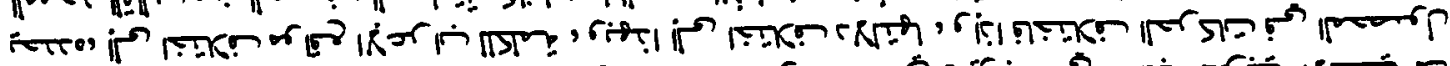

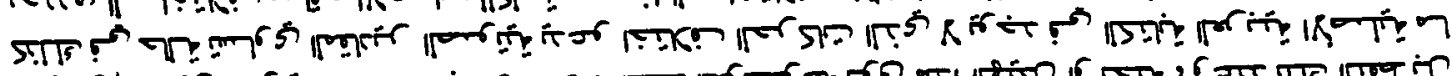

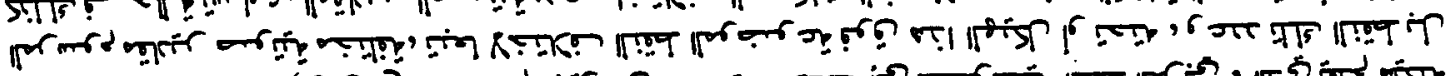

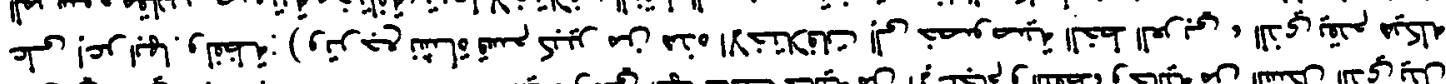
|

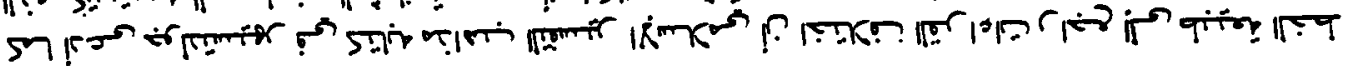

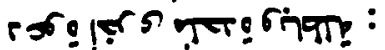

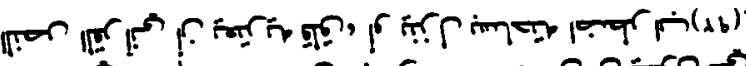

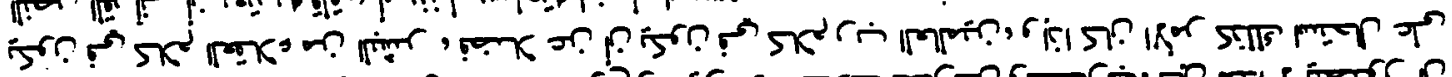

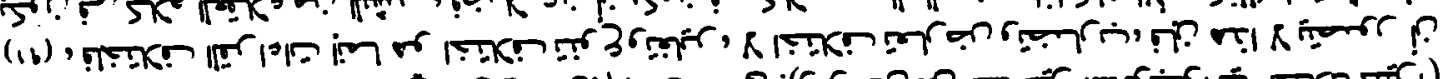

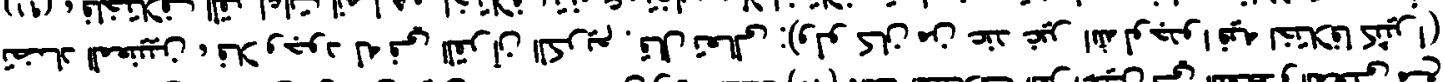

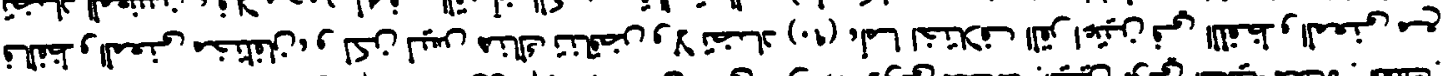
"

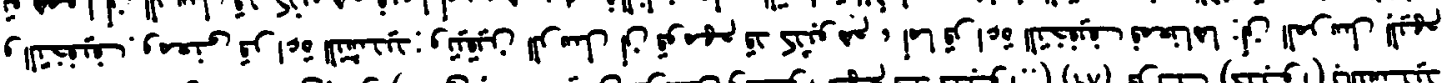

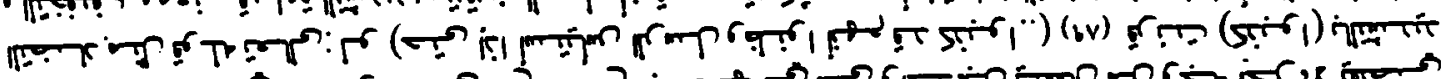
ITUm

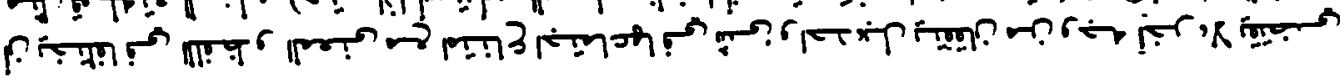

(2) r

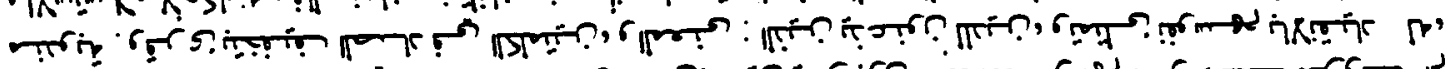

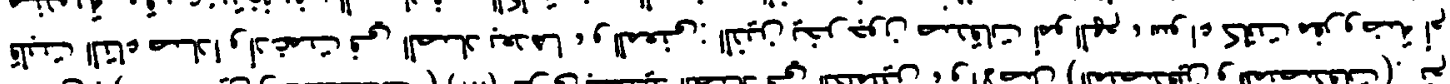

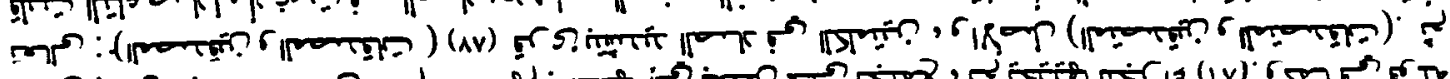

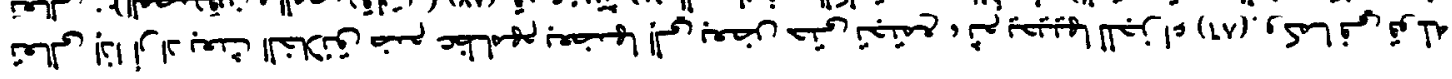




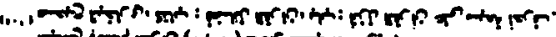

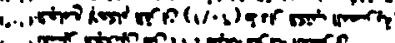

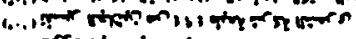

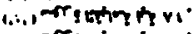

1...,

10.1 oritutinth b.

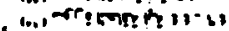

i.,

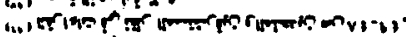

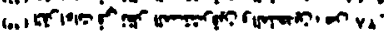

(T)

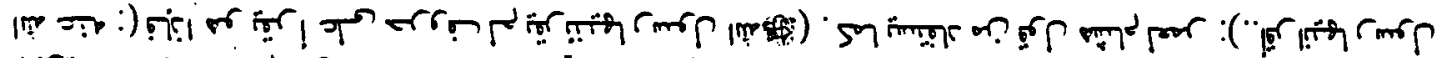

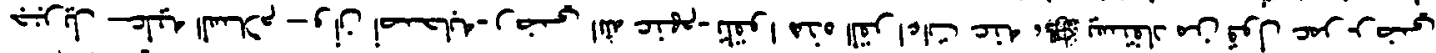
然 IT⿱

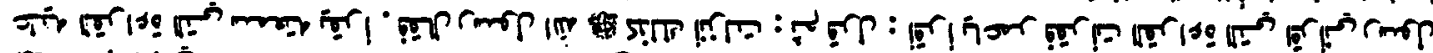

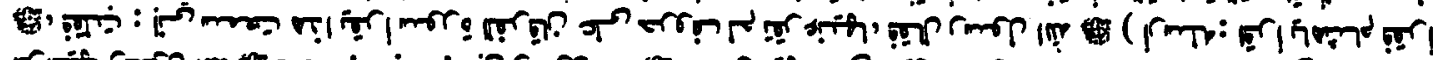

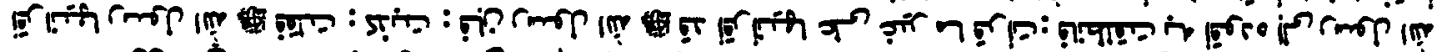

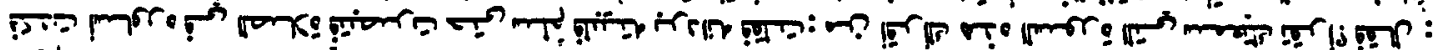

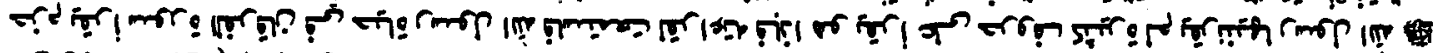
$=$ ?

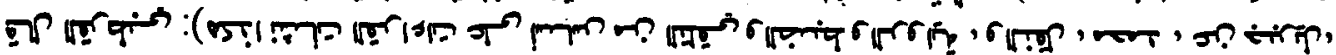

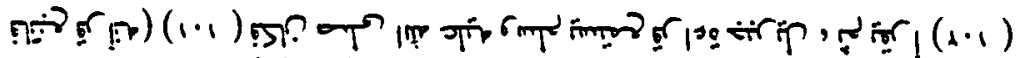

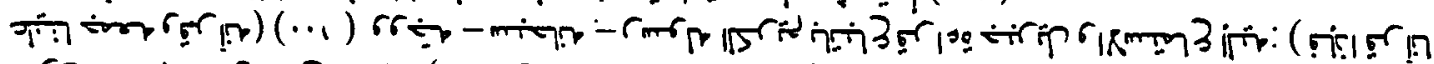

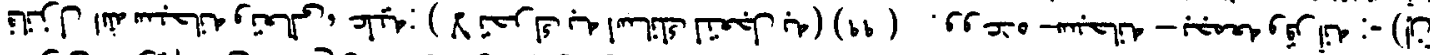

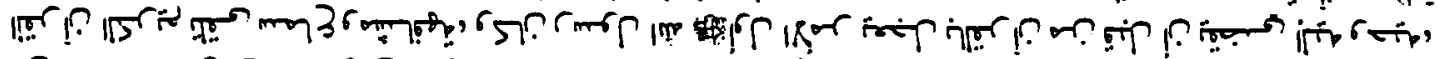

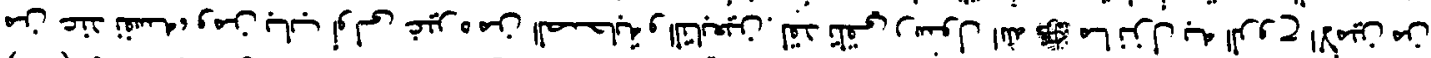

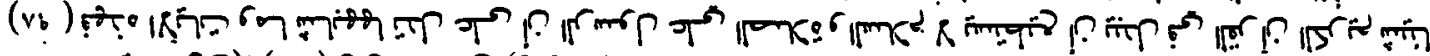

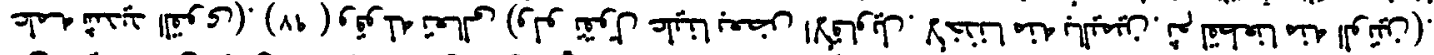

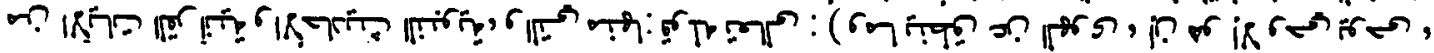

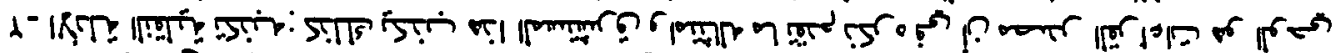

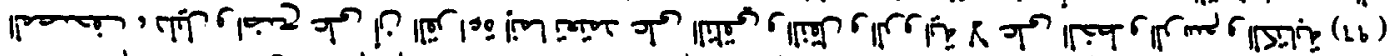

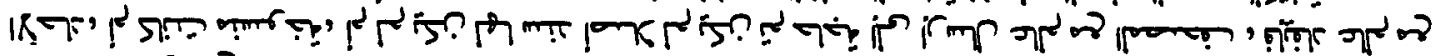

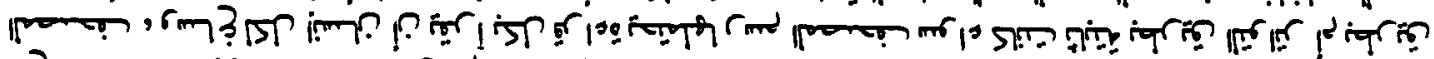

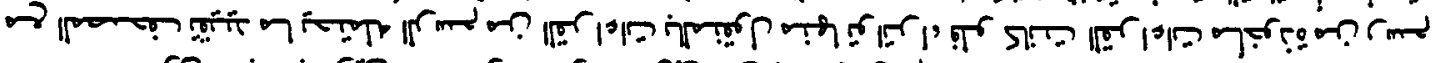

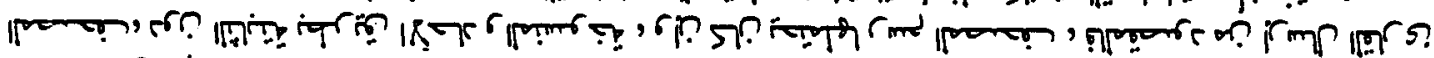

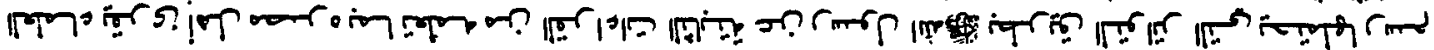
"

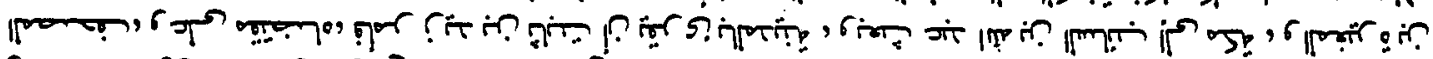

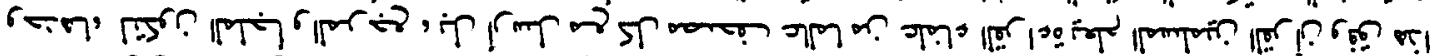

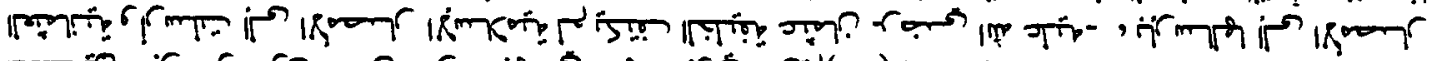
ו 


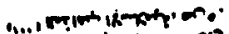

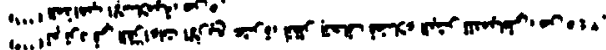

lo... in 1 in

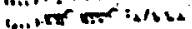

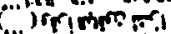

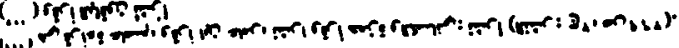

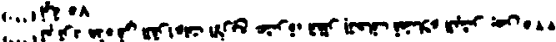

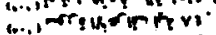

a.,

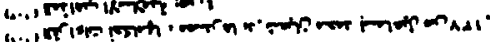

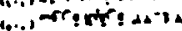

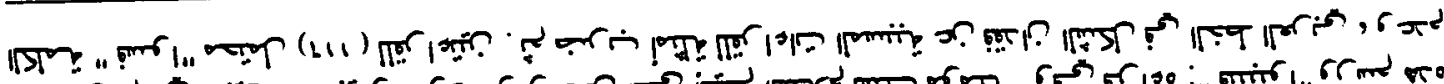

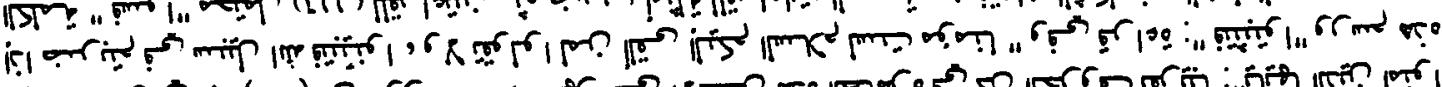
*

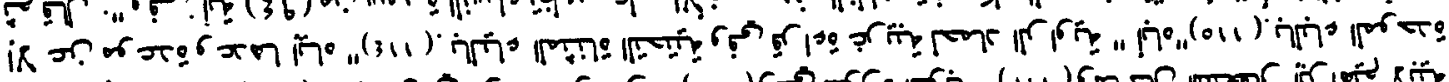

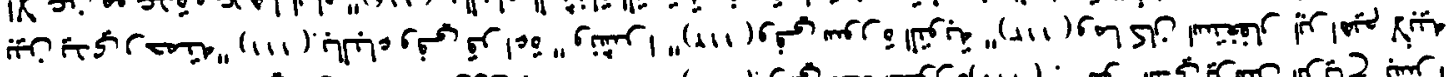

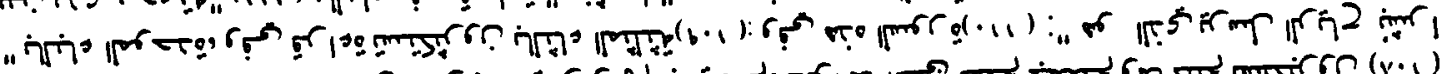
ाएव "

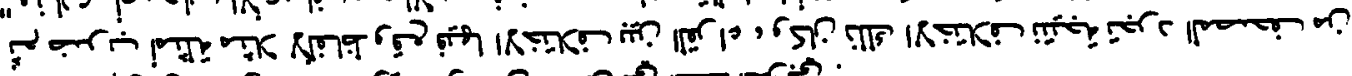

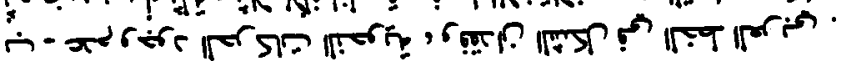

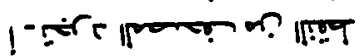

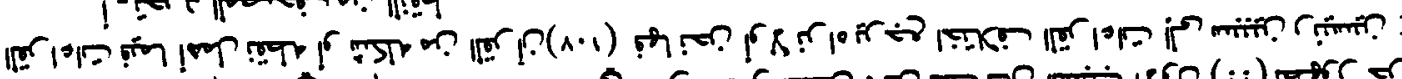

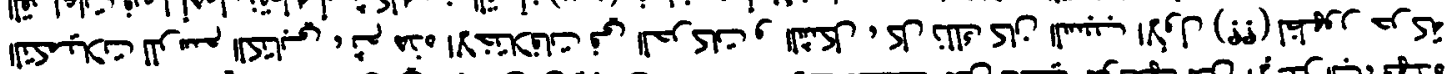

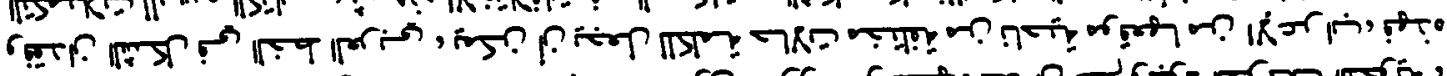
|r |

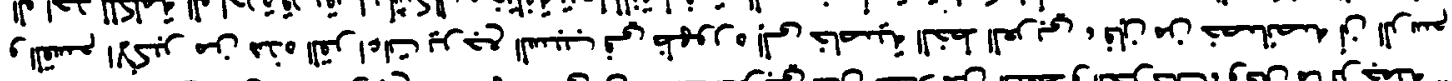

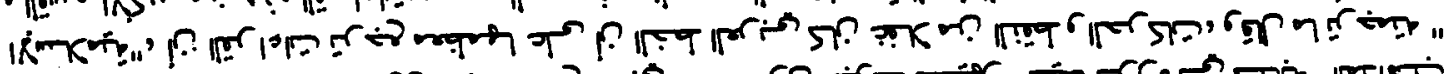

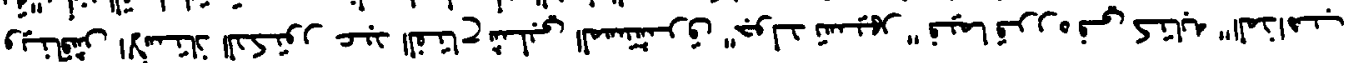
Mrompor or

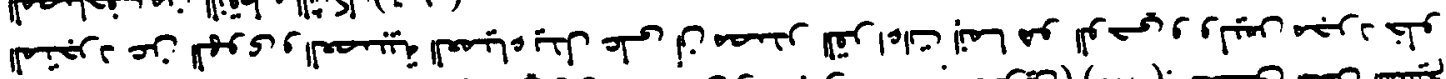

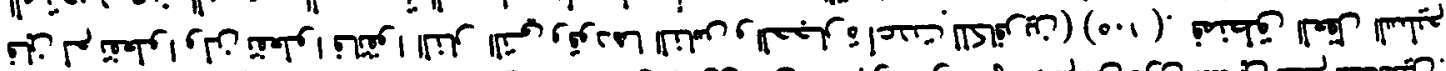
"

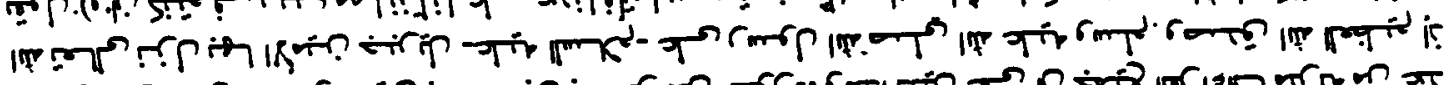

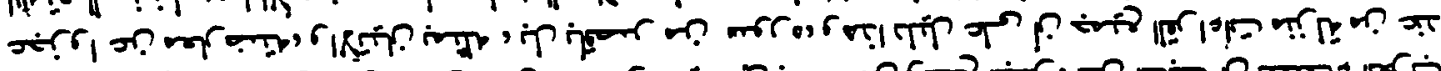
iv ". व C.

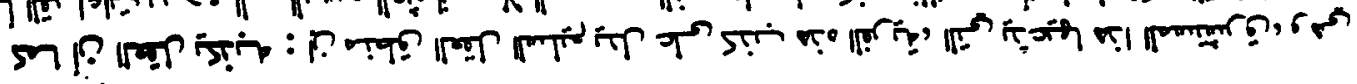

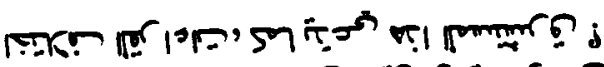
, orre

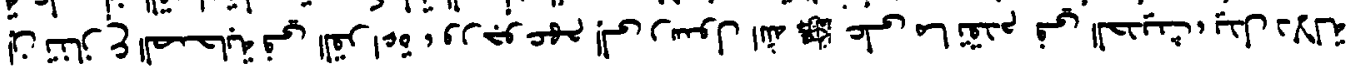




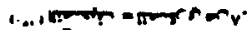

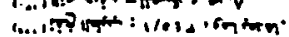

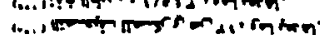

(a.,

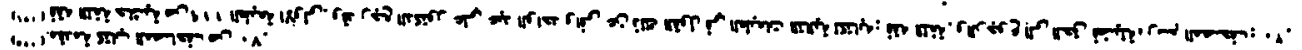

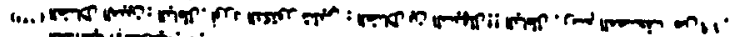

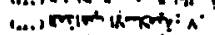

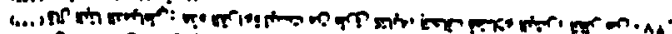

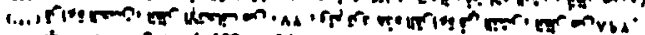

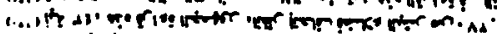

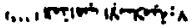

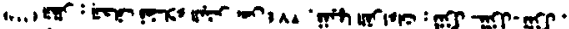

I.... in : ${ }^{\circ}$

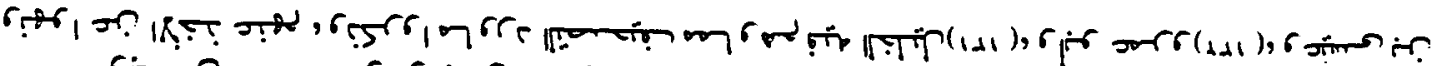

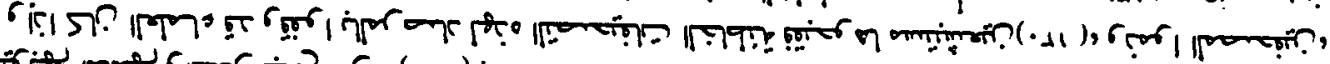

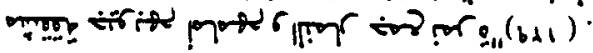

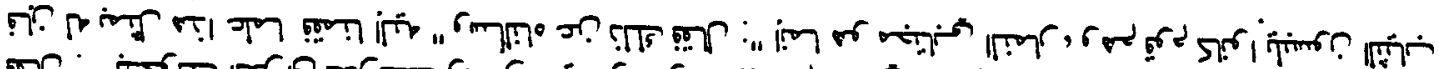

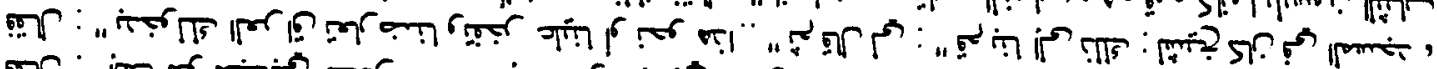

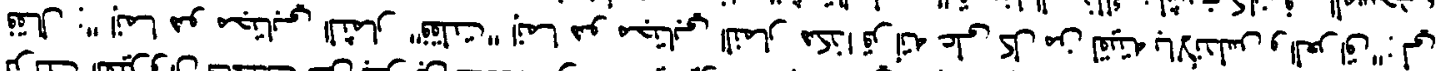
ז

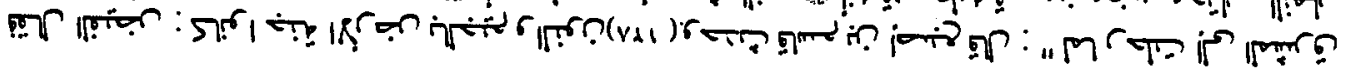

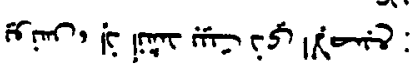

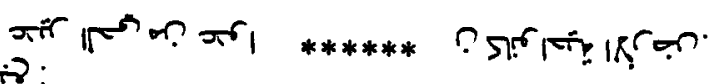

15rivots on

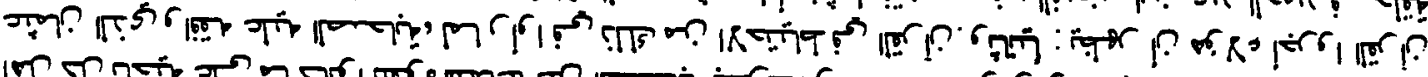

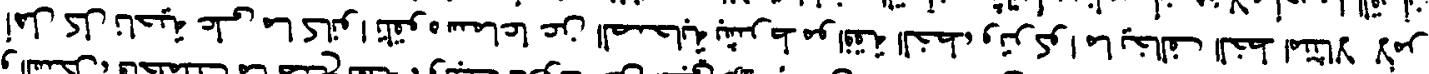

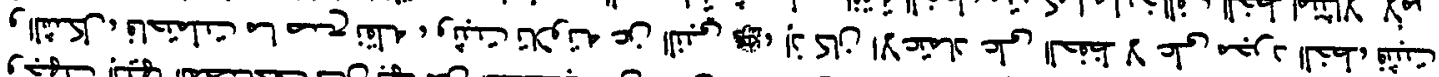

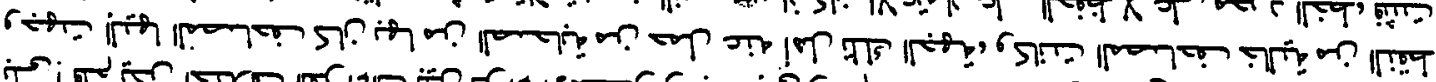

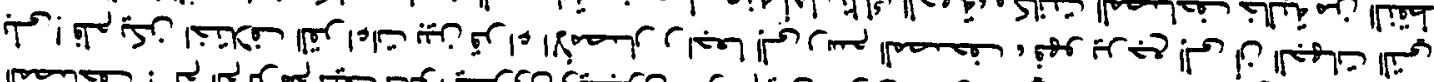

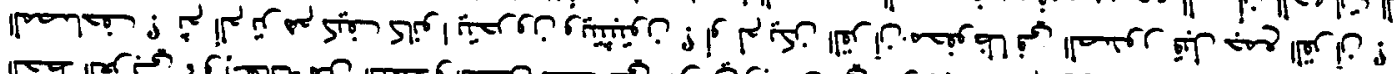

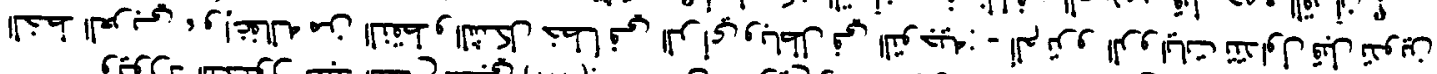

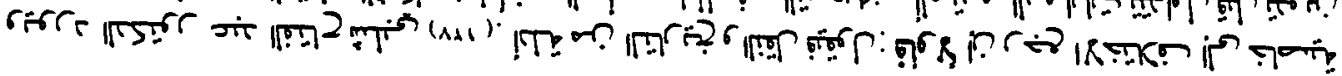

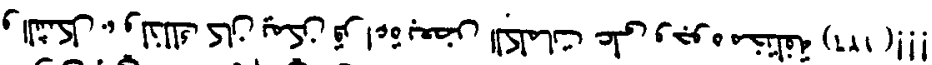

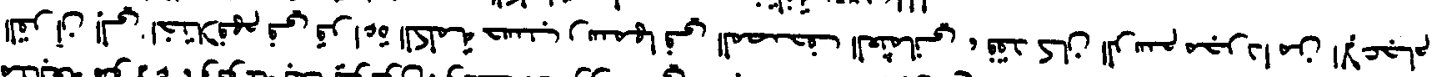

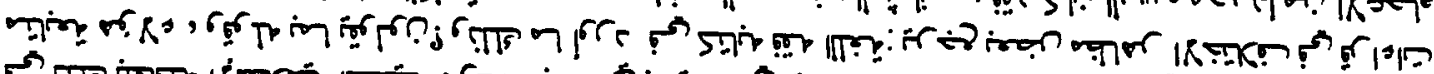

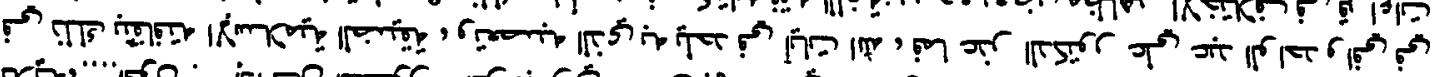

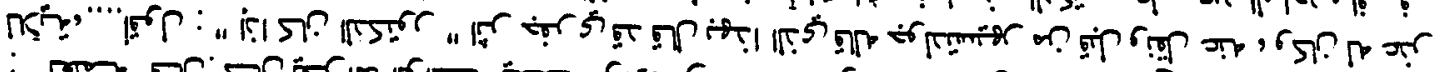

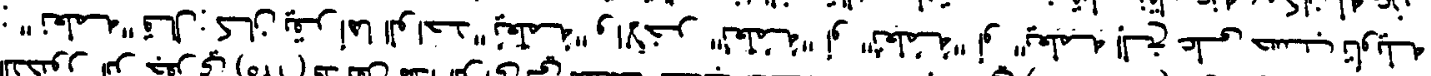

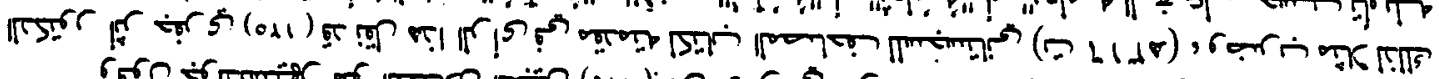

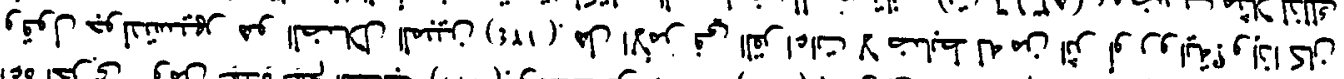

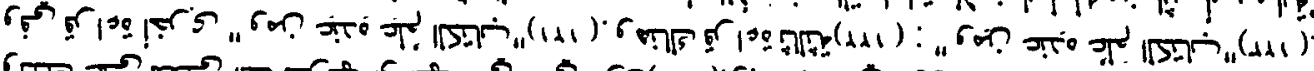

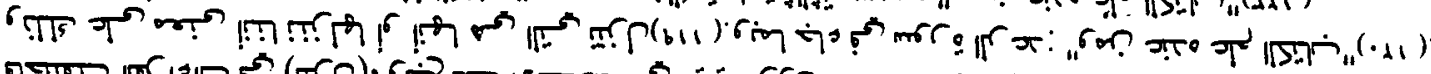

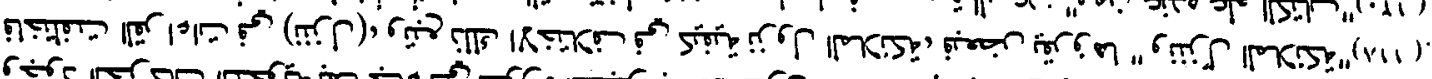

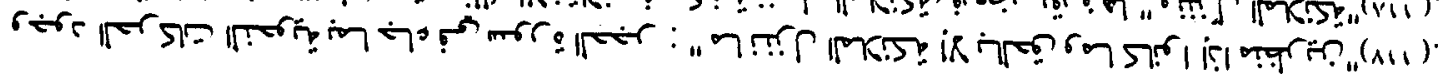


$(1,)+.\left(M_{2}\right)$

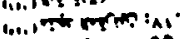

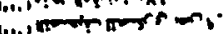

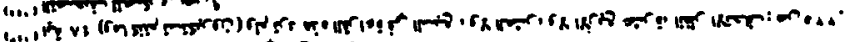

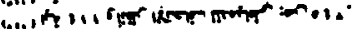

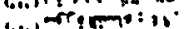

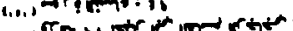

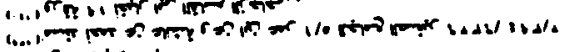

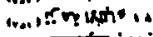

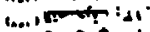

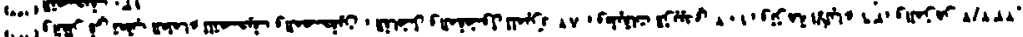

(a.i)

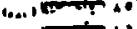

$10.1010+10$

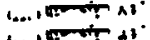

(1,..1

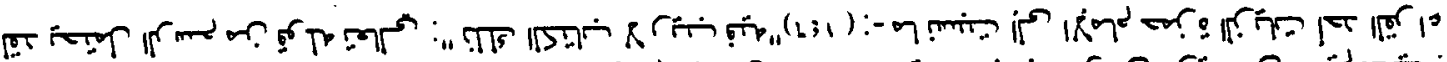

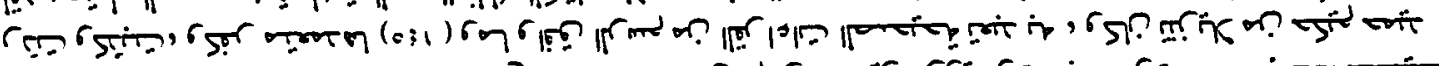

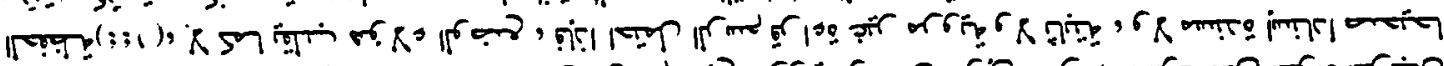

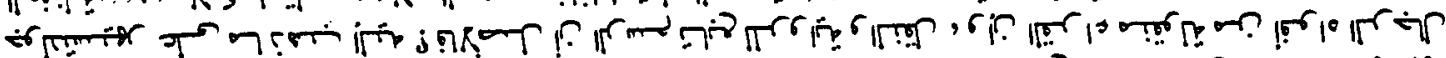

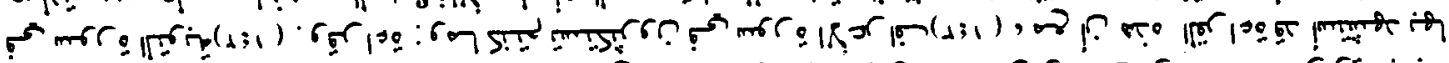

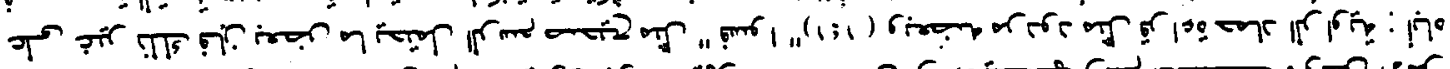

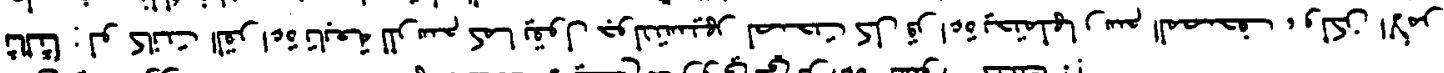

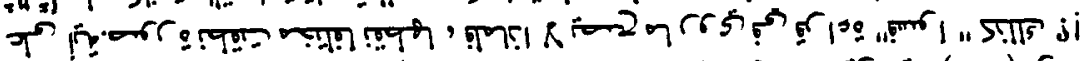

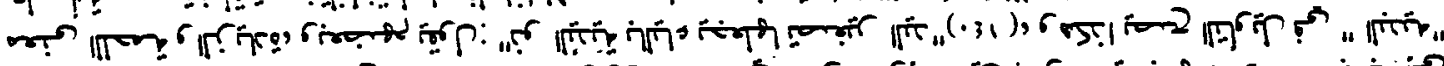

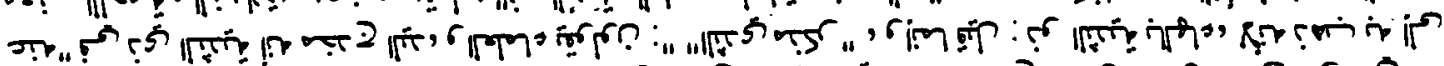

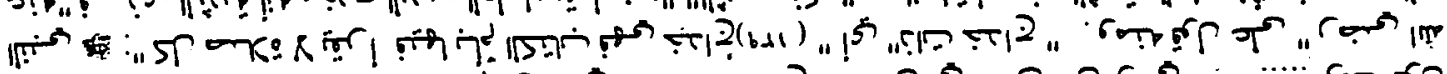
-

ormogra ja

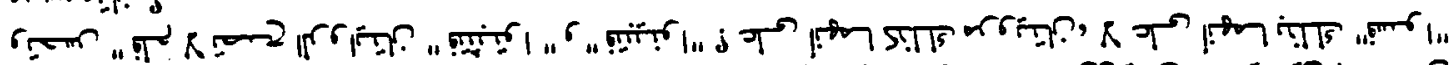

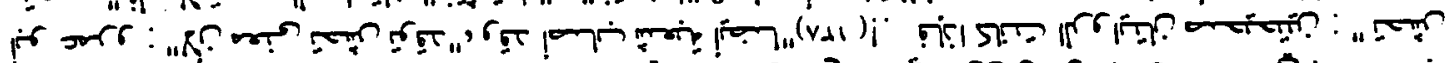

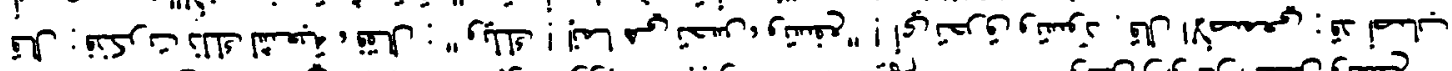
"

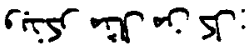

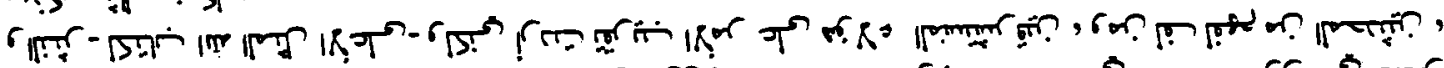

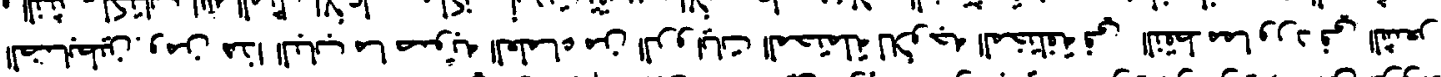
por

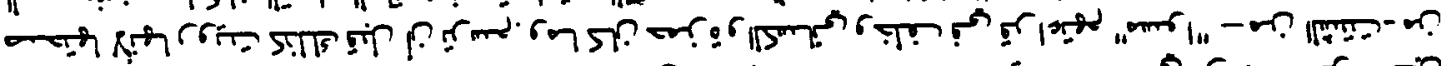

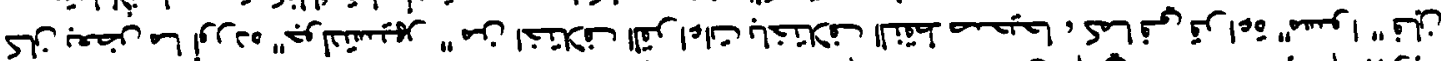

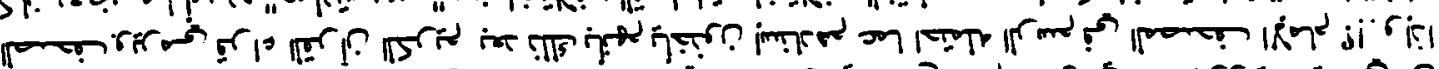

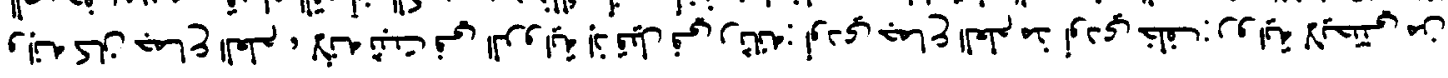

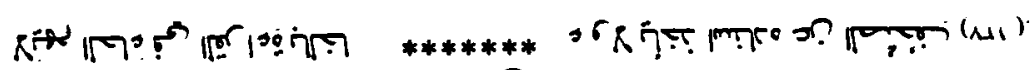

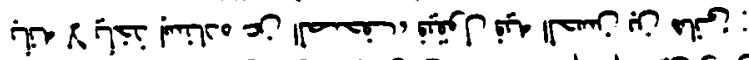

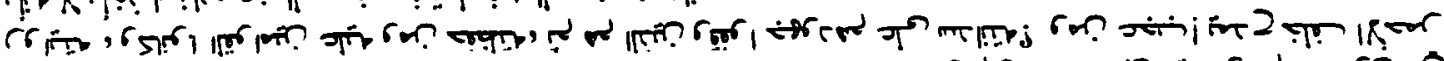

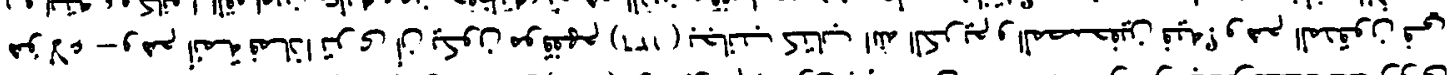

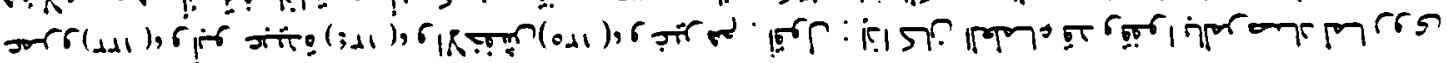


cisingme.

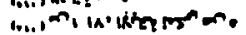

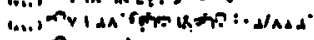

c....ind 1.10

(a...)

(i...

…. $\sim$ ?

w...

i...

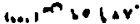

$\left.1 . ., 1^{-n}+1\right)^{\circ}$

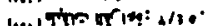

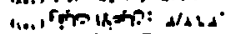

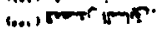

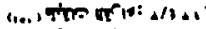

1.... 1

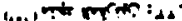

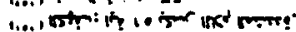

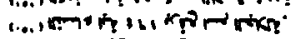

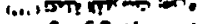

in, $r=0$ rewh.

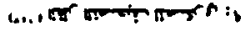

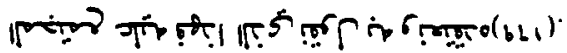

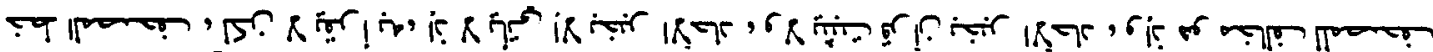

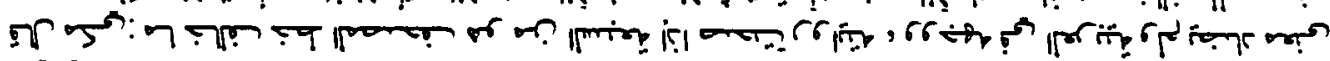

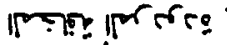

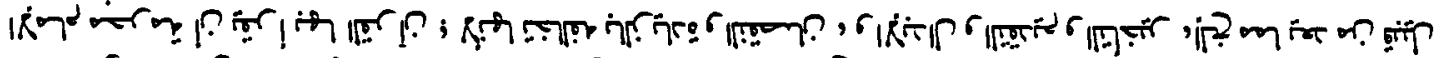

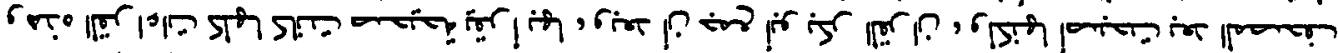

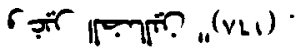

|

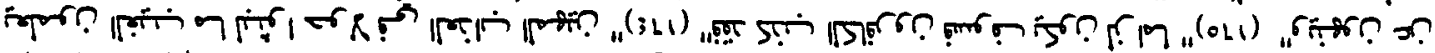

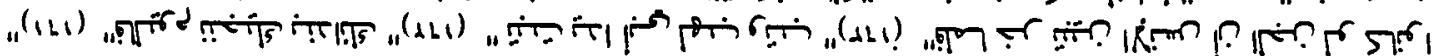

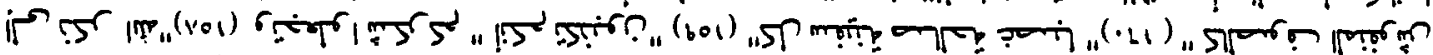
ड़ाइ

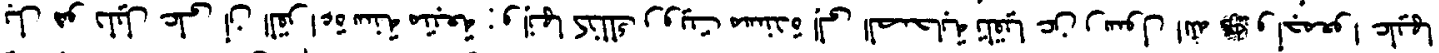
,

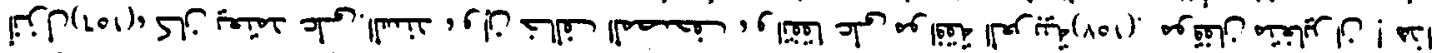

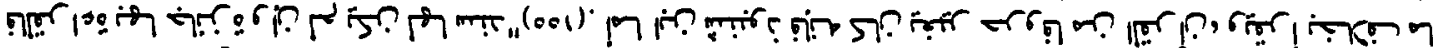

IM-

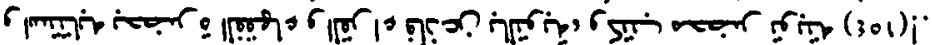

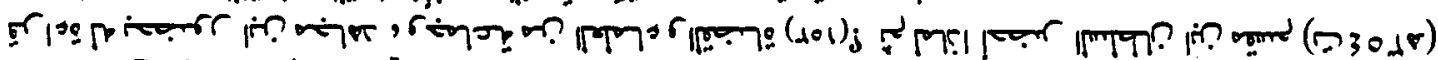

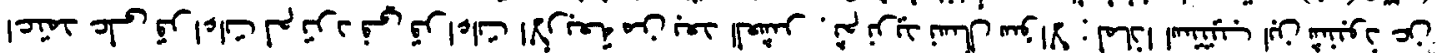

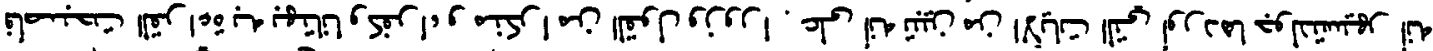

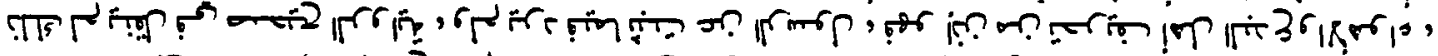

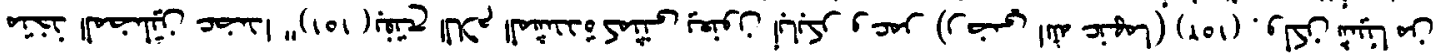
"

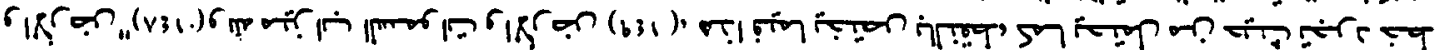

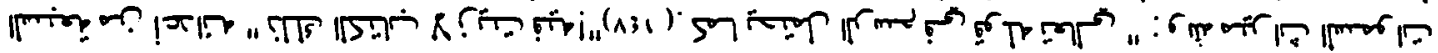




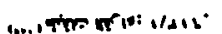

i....

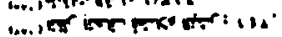

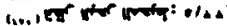

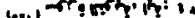

co...

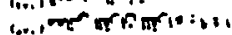

co..

i...,

1..., imm: :- ?

c...

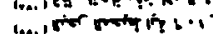

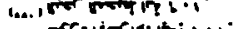

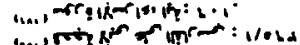

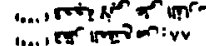

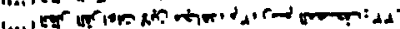

i..., 113

(...) $m_{11}+1 \alpha^{\circ}$

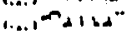

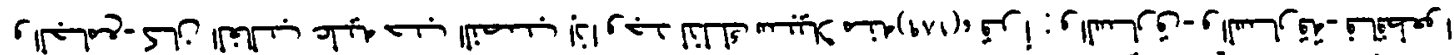

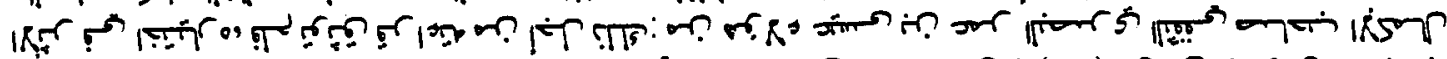

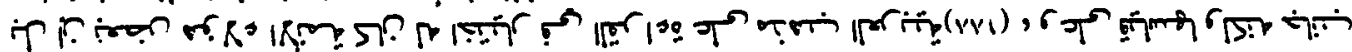

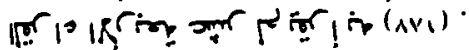

की

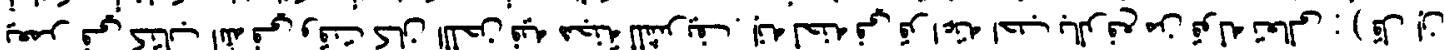

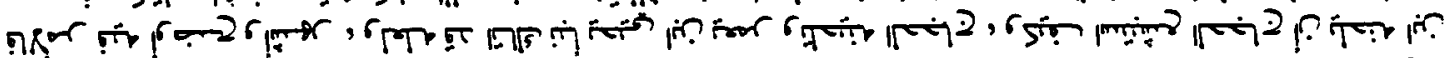

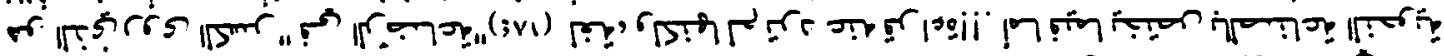

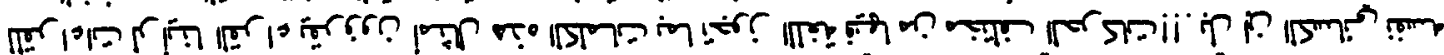

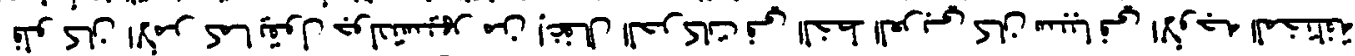

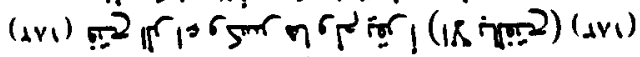

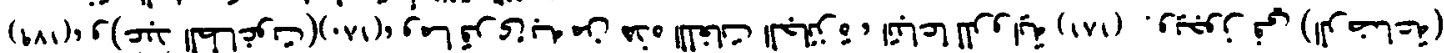

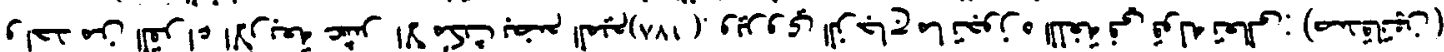

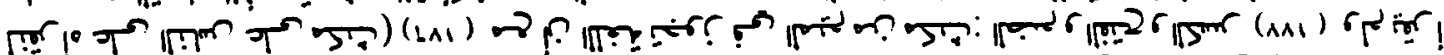

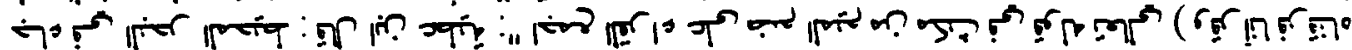

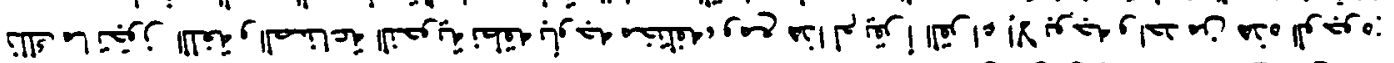

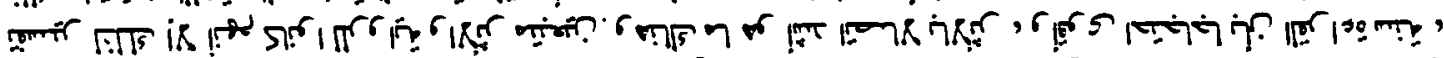

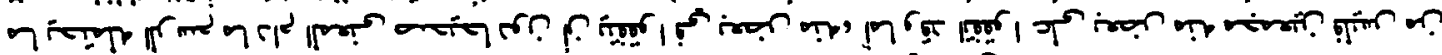

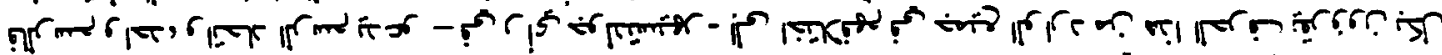

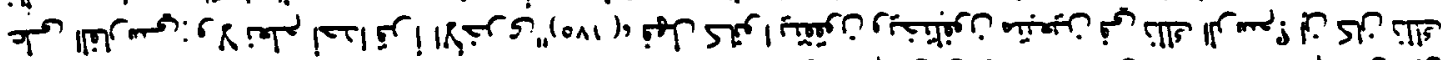
年

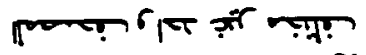

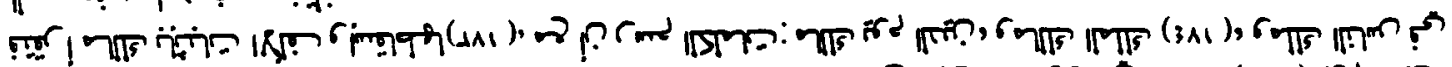

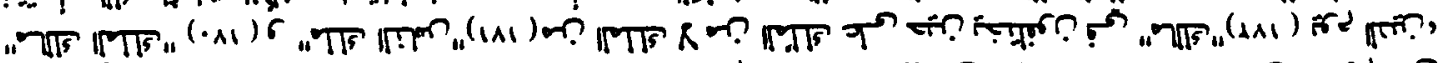

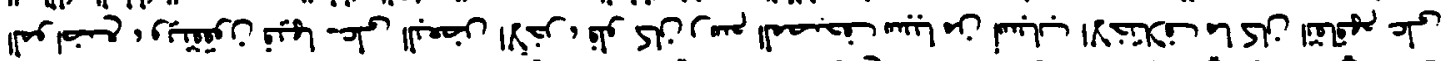

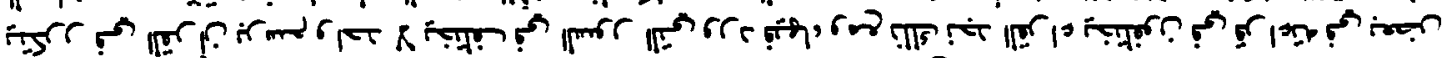

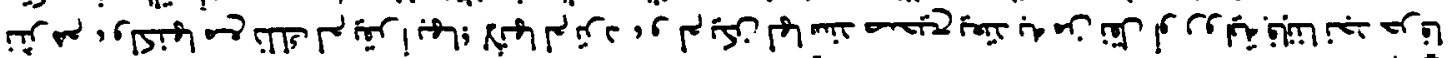

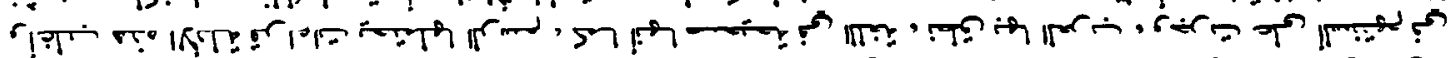

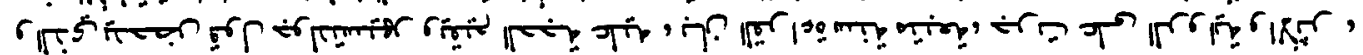




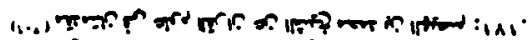

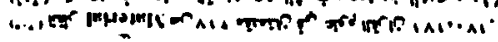

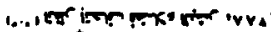

i... on wo for of io :ve

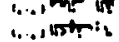

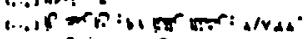

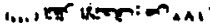

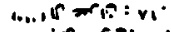

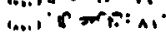

1..., is $=0$ a

…. (m)

1... the w. W1

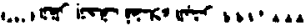

c...ing

i.... $m$ is is is

n....

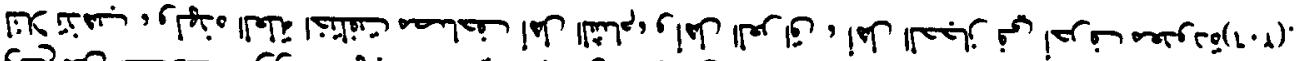

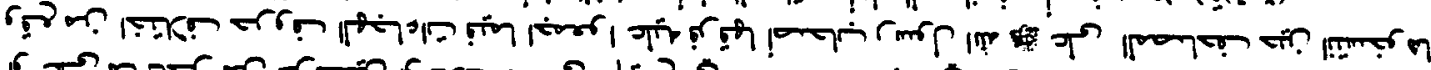

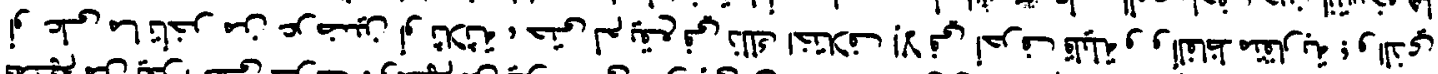

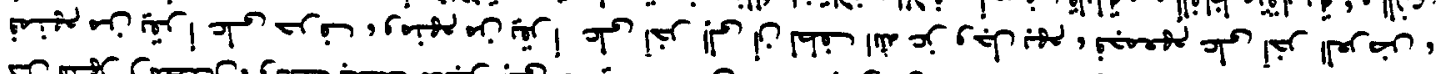

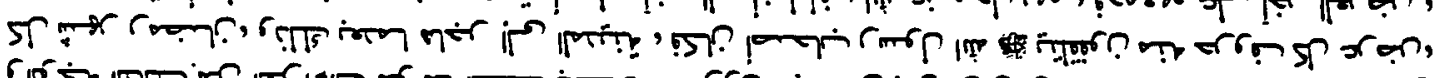

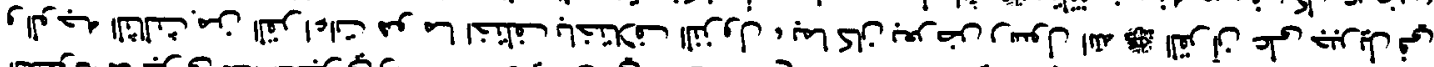
"

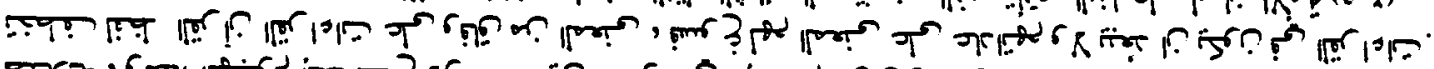

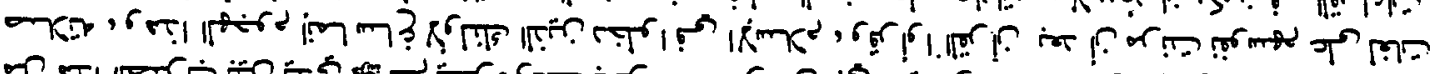

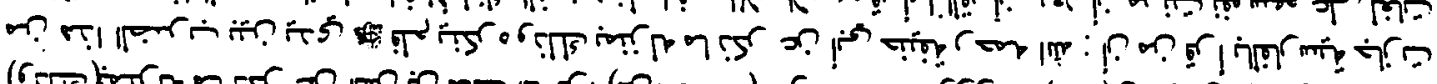

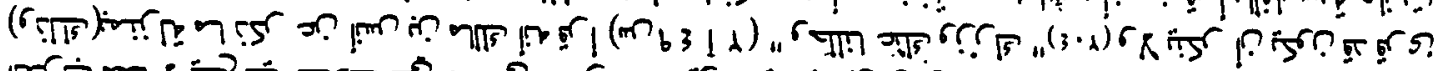

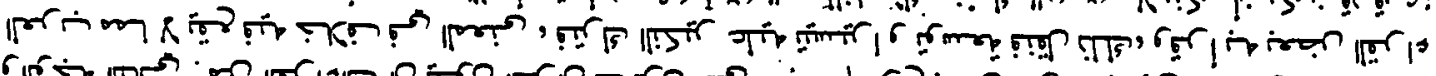

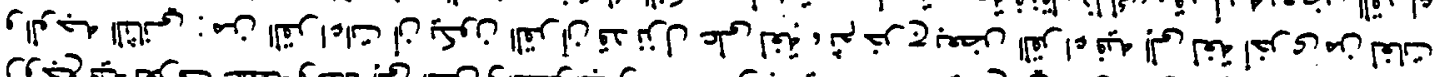

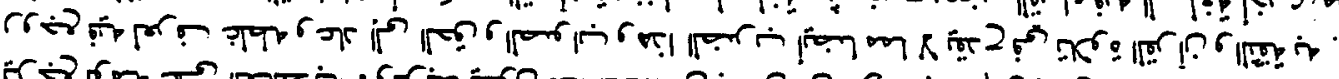

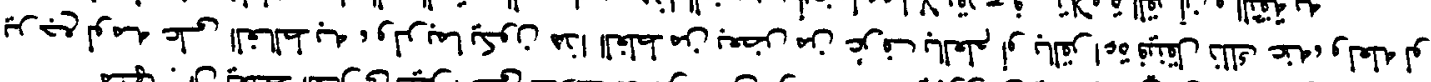

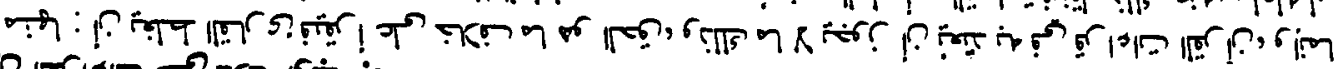

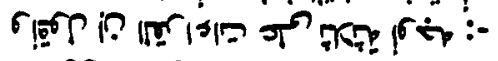

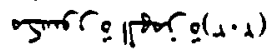

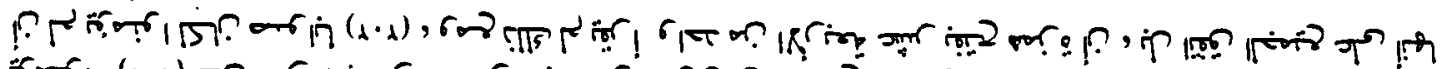
بs

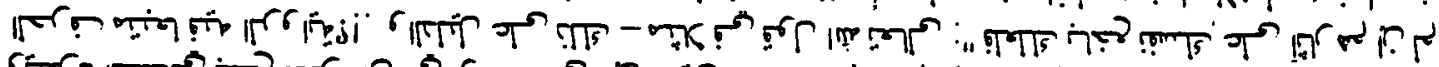

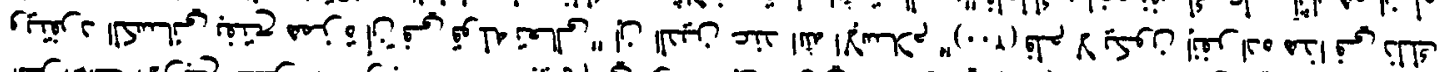

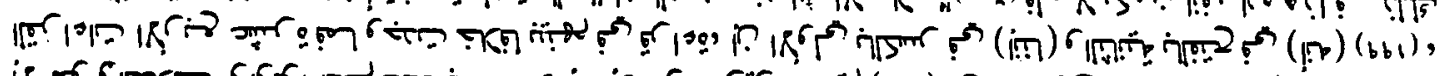

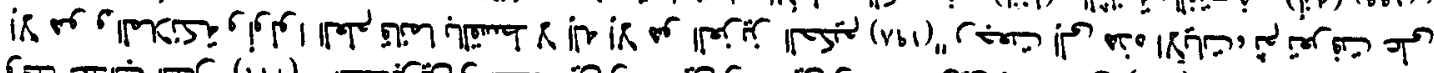

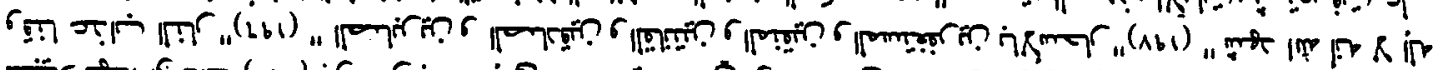

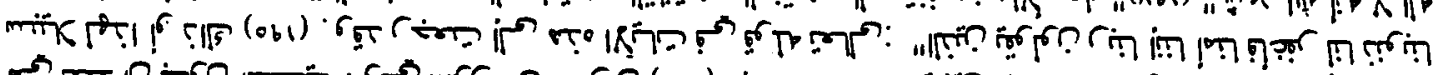

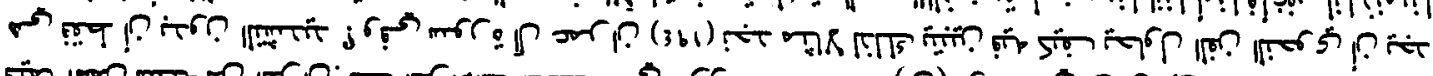

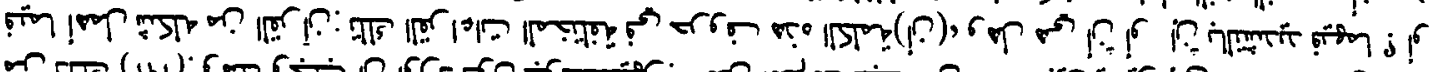

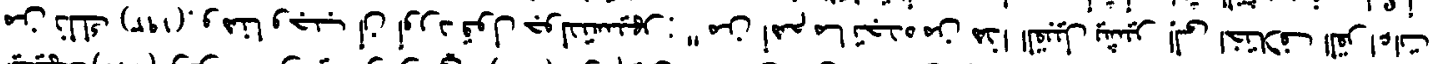

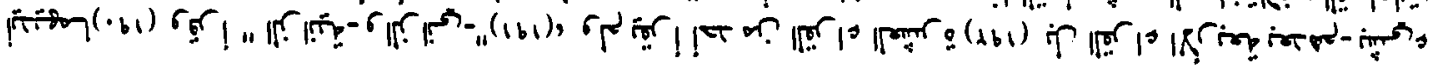


ariuguty (v)

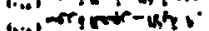

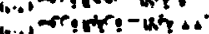

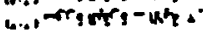

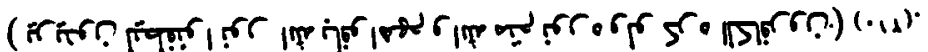

3- 3 -

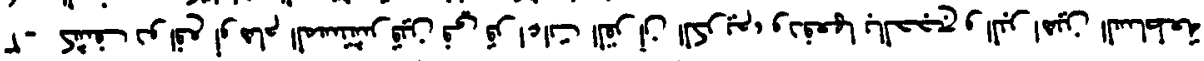

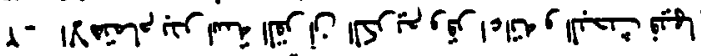

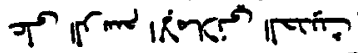

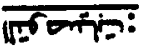

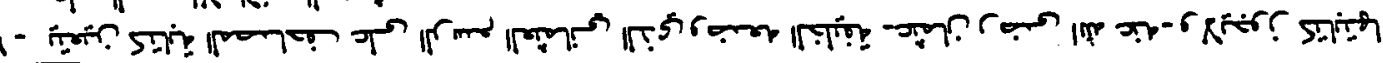

If

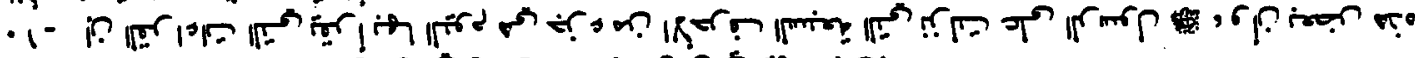

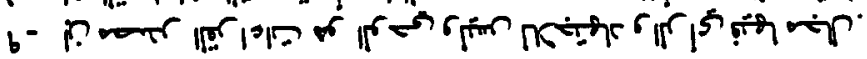

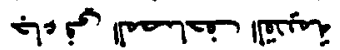

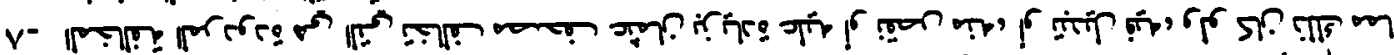
7) ;

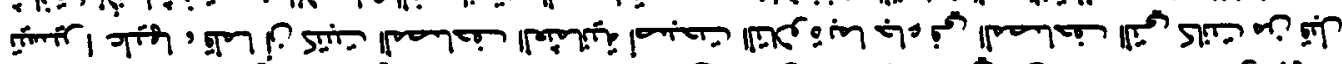

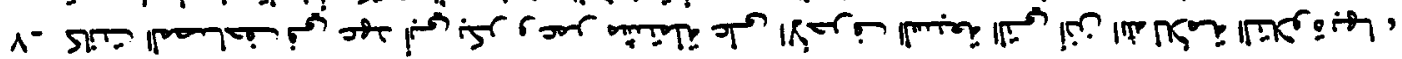

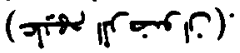

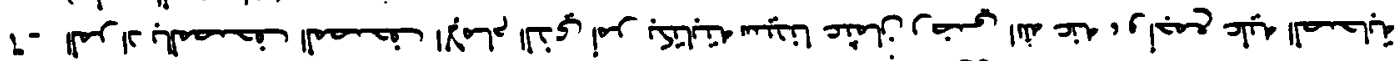

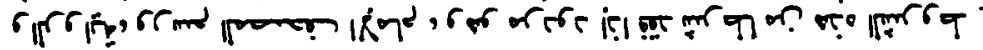

- - -

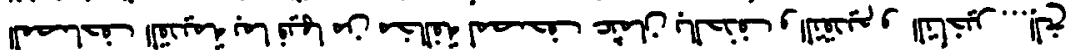

3- - -

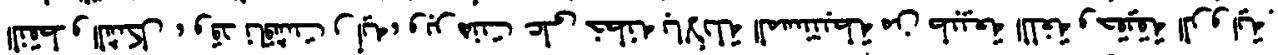

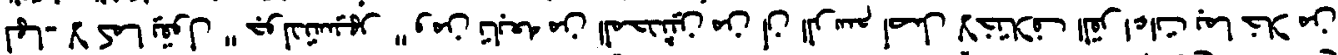
|

d

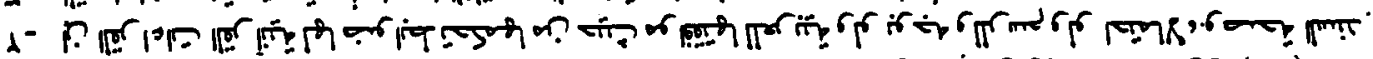

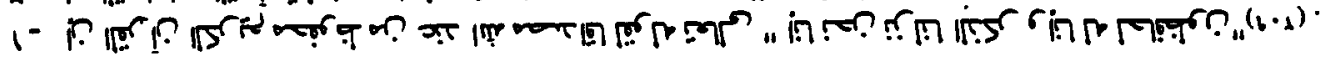

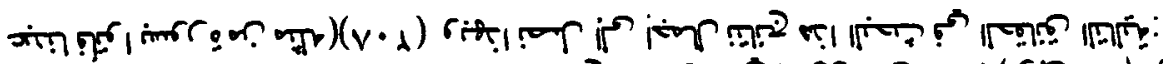

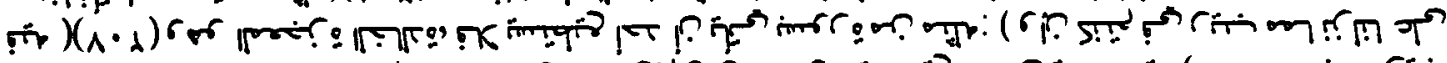

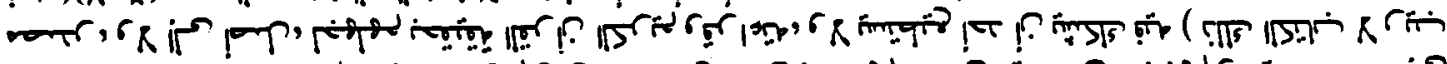

"

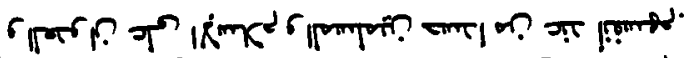

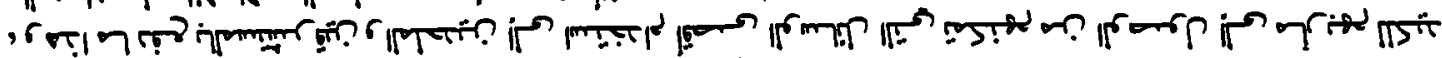

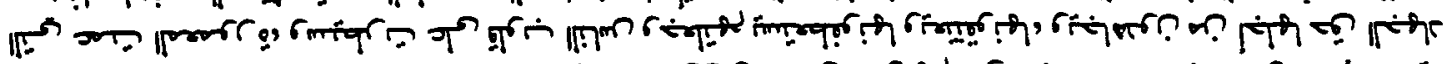

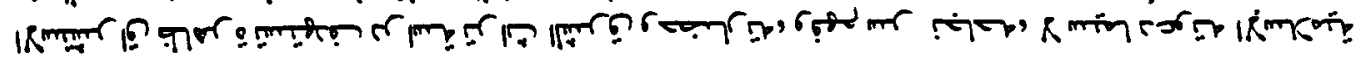
1ำ? 


\section{$d d$}

\begin{tabular}{|c|c|}
\hline 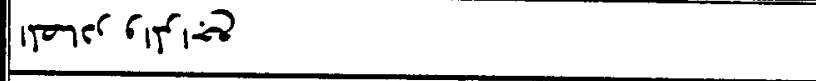 & $\cdot \lambda$ \\
\hline Ifrote & $b 1$ \\
\hline $\min r^{2}$ & 61 \\
\hline Itages & $b 1$ \\
\hline 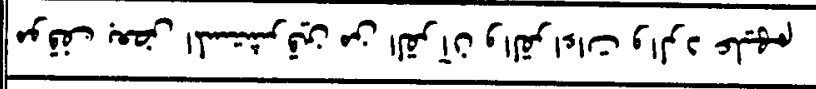 & $b$ \\
\hline 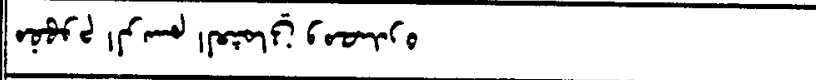 & 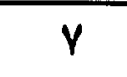 \\
\hline 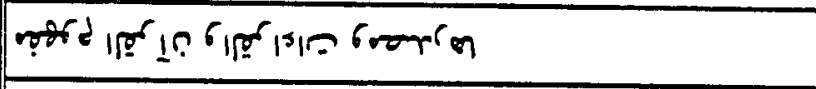 & $\Lambda$ \\
\hline \multicolumn{2}{|c|}{ 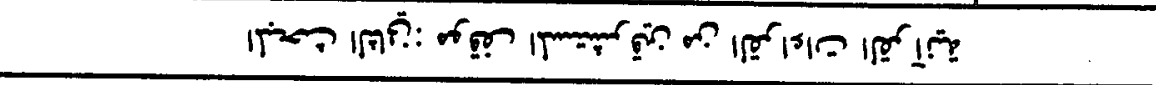 } \\
\hline 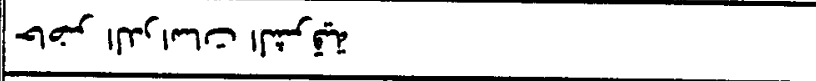 & $L$ \\
\hline |م & $b$ \\
\hline 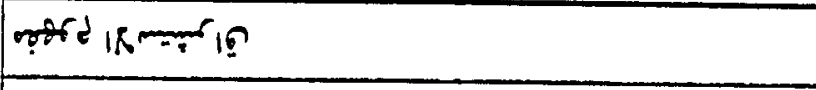 & 0 \\
\hline \multicolumn{2}{|c|}{$\lim _{18}$} \\
\hline Ieror & $d$ \\
\hline 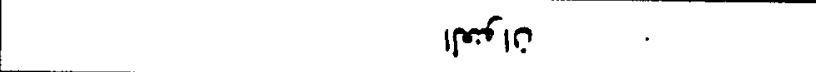 & 1ropes? \\
\hline
\end{tabular}

